\title{
Basis of Bone Metabolism around Dental Implants during Osseointegration and Peri-Implant Bone Loss
}

\author{
Angel Insua, DDS, MS, $\mathrm{PhD}^{1}$, Alberto Monje, DDS, MS ${ }^{2}$, Hom-Lay Wang, DDS, MS, $\mathrm{PhD}^{3}$, Richard J. \\ (P) \\ Miron, dr. med. dent., DDS, MSc, $\mathrm{PhD}^{4}$ \\ ${ }^{1}$ Research fellow, Department of Periodontics and Oral Medicine, The University of Michigan. \\ Ann Arbor, MI, USA \\ ${ }^{2}$ Research fellow, Department of Periodontics and Oral Medicine, The University of Michigan. \\ Ann Arbor, MI, USA. \\ 3 Professor and Director of Graduate Periodontics, Department of Periodontics and Oral \\ Medicine, University of Michigan School of Dentistry, Ann Arbor, MI, USA. \\ ${ }^{4}$ ITI scholar, Department of Periodontics and Oral Medicine, The University of Michigan. Ann \\ Arbor, MI, USA, Research fellow, Department of Periodontology, Nova Southeastern University, \\ Fort Lauderdale, Florida, USA.

\section{Author contributions:} \\ A. Insua contributed to conception, design, draft and critical review of manuscript; A. Monje \\ contributed to conception, design, draft and critical review of manuscript; H-L. Wang, \\ contributed to the critical review of manuscript and funding; Richard Miron contributed to \\ design, draft and critical review of manuscript.
}

Conflict of interest: The authors do not have any financial interests, either directly or indirectly, in the products or information listed in the manuscript. This article was partially supported by the University of Michigan Periodontal Graduate Student Research Fund.

This is the author manuscript accepted for publication and has undergone full peer review but has not been through the copyediting, typesetting, pagination and proofreading process, which may lead to differences between this version and the Version record. Please cite this article as doi:10.1002/ jbm.a.36060. 


\section{Corresponding author:}

Angel Insua-Brandariz

Department of Periodontics and Oral Medicine

University of Michigan School of Dentistry

1011 North University Avenue

Ann Arbor, Michigan 48109-1078, USA.

TEL: (734) 763-3383; FAX: (734) 936-0374

E-mail address: ainsua@umich.edu

Word count: 6608

Tables and figures: 1 table and 3 figures.

MeSH Key words: Bone remodeling, osseointegration, peri-implant endosseus healing, dental implant. Running title: Basis of Bone Metabolism around Dental Implants during Osseointegration and PeriImplant Bone Loss.

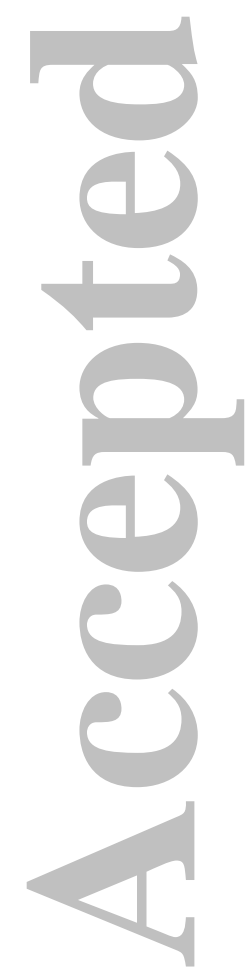

John Wiley \& Sons, Inc. 


\title{
Basis of Bone Metabolism around Dental Implants during Osseointegration and Peri-Implant Bone Loss
}

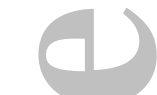

Abstract

Background: Despite the growing number of publications in the field of implant dentistry, there are limited studies to date investigating the biology and metabolism of bone healing around dental implants and their implications in peri-implant marginal bone loss.

Purpose: The aim of this review article is to provide a thorough understanding of the biological events taking place during osseointegration and the subsequent early and late phases of bone remodeling around dental implants. An update on the coupling mechanism occurring during bone resorption-bone remodeling is provided, focused on the relevance of the osteocytes, bone lining cells and immune cells during bone maintenance.
\end{abstract}

Material and methods: An electronic and manual literature search was conducted by three independent reviewers in several databases, including MEDLINE, EMBASE, Cochrane Central Register of Controlled Trials and Cochrane Oral Health Group Trials Register databases for articles up to September 2016 with no language restriction.

Results: Local bone metabolism is subject to signals from systemic calcium-phosphate homeostasis and bone remodeling. Three areas of interest were reviewed due to recent reported compromises in bone healing including the putative effects of 1) cholesterol, 2) hyperlipidemia and 3) low vitamin D intake. Moreover, the prominent influence of osteocytes and immune cells is discussed as being key regulators during dental implant osseointegration and maintenance. These cells are of crucial importance in the presence of biofilm accumulation and their associated byproducts that leads to hard and soft tissue breakdown; the so called peri-implantitis.

Conclusion: Factors that could negatively impact osteoclastogenesis or osteal macrophage activation should be monitored in future research including implant placement/torque protocols, bone characteristics, as well as meticulous maintenance programs to favor osseointegration and future long-term stability and success of dental implants. 


\section{Introduction}

Primary or mechanical stability in implant dentistry is regarded as a prerequisite for successful osseointegration. The alveolar bone architecture of the implant drilling site dictates the success of anchored endosseous implants. Immediately and up to several months afterwards, a series of cellular and molecular events take place where host tissues biologically integrate the alloplastic material into the native bony structure. While cortical bone has the function of withstanding torsional loading and provides higher initial stability, cancellous bone is richer in vascular canals and thus, vasculature to supply mesenchymal progenitor cells. In this sense, the complex and dynamic process of osseointegration may occur via contact osteogenesis, where the implant surface is populated by bone cells after fixation to form de novo bone, or via distance osteogenesis, where bone formation is preceded by the osteoclastogenesis of the existing tissue. ${ }^{1}$

Nowadays, peri-implant disease does not represent an uncommon condition where, with no hesitation, plaque and its byproducts in a susceptible host are the primary etiology, as it has been demonstrated its cause-effect relationship. ${ }^{2}$ Moreover, certain risk factors/indicators such as smoking or history of periodontal disease have been strongly linked to the prevalence of periimplantitis. ${ }^{3,4}$ Nonetheless, other factors such as material biocompatibility, implant placement and material degradation / titanium particle release have been regarded as other potential factors associated with peri-implant bone loss as a prominent matter of discussion of its implication on osseointegration breakdown even in the lack of irritants. ${ }^{5}$

Into the bargain, early peri-implant marginal bone loss was controversial due to limited knowledge on how hard tissue remodels as a consequence of the biological width adaptation. This has resulted in the development of novel modifications to the implant-abutment connections as well as an evolution towards hydrophilic and bioactive implant surfaces for early osseointegration. Nevertheless, a tight link between the osteogenic and osteoclastogenic pathways modulated by complement factor-3 signaling seems to play a further role on osteolysis led by monocytes/macrophages later discussed in this article. Moreover, the inflammatory response may be exacerbated by tissue trauma such as overheating or compression necrosis (i.e., high insertion toque). These might aggravate the peri-implant bone loss even in an aseptic environment, and worsen the implant prognosis due to the increased exposure of developing a later anaerobic infection, namely peri-implantitis. Therefore, the aim of this narrative review is to provide an updated understanding of the biological events that take place during implant osseointegration and subsequent early and late bone remodeling around implants.

\section{Biology of the bone remodeling}




\subsection{Role of osteocytes and bone lining cells in the remodeling process}

Osteocytes are the pivotal cells in the regulation of bone mass and structure along with osteoblasts and osteoclasts. ${ }^{6}$ Osteoblasts are derived from mesemchymal stem cells and synthesize new bone matrix. ${ }^{7}$ Osteoclasts are terminally differentiated multinucleated cells from the monocyte-macrophage lineage and beyond their role in bone resorption, these cells are also a source of cytokines that play an important role in bone homeostasis. ${ }^{8}$

Osteocytes are terminally differentiated osteoblasts with a primary function to support bone structure and mechanosensation. ${ }^{7}$ They act as regulators of bone remodeling by modulating osteoclast and osteoblast activities. ${ }^{8}$ These stellate-shapped cells are located within lacunae surrounded by mineralized bone matrix and present with connections through cytoplasmic prolongations with surface bone lining cells and also with bone marrow. ${ }^{9}$

Bone lining cells (BLC) are cells involved in bone formation much like pre-osteoblasts, osteoblasts and osteocytes. ${ }^{10}$ They are characterized by a flat-shaped architecture along bony surfaces $^{8}$ (Figure 1) and may be considered as latent osteoblasts. ${ }^{11}$ In human cancellous bone, around $65 \%$ of osteoblasts undergo apoptosis with approximately $30 \%$ differentiating into osteocytes, ${ }^{12}$ and the reduced remnants becoming BLC and chondroid-like cells. ${ }^{10,12}$ BLCs maintain their proliferative capability and often differentiate into other osteogenic cells. ${ }^{13,14}$ Various studies have shown that some factors can induce their proliferation prior to bone formation, ${ }^{15}$ while mature osteolasts are unable to divide. ${ }^{10}$ Osteoblasts may also undergo a quiescent stage when there is no bone resorption or remodeling, ${ }^{13}$ but the function of BLCs might be more complex than a simple latent state, ${ }^{16}$ including catabolic and anabolic bone processes ${ }^{15}$ and rapid bone formation under osteogenic signaling. ${ }^{16}$

\section{2 Bone remodeling process}

As bone remodeling is a complex process previously discussed in various other excellent review articles ${ }^{117}$ and exceeds the limits of this review, we focus specifically on the pivotal implications of osteocytes and BLCs during this process (Figure 2 A). External factors such as mechanichal loading, irradiation, parathyroid hormone (PTH), fibroblast growth factor-2 (FGF2), sclerostin inhibition or inflammation may lead BLCs to exit the quiescent stage into an active function phase by reforming cuboidal appearance and their secretory capability. ${ }^{8,15,18}$ The presence of BLCs observed histologically indicates a strong sign of osteogenic potential ${ }^{13}$ and often regarded as a major source of osteoblasts and proliferating pre-osteoblasts in the adult population. ${ }^{15}$ This prominent role in new bone formation was previously highlighted ${ }^{12,16}$ when rapid bone formation after mechanical loading without previous bone resorption was observed. 
Early peak of bone formation after three days was only possible if BLCs underwent reactivation and reaquired their secretory capacities. ${ }^{12,16}$

Moreover, BLCs exert a prominent function during bone resorption ${ }^{19}$ demonstrated by their ability to express key ostoclastogenesis markers including macrophage colony -stimulating factor receptor (M-CSFR) and receptor activator of nuclear factor kappa-B ligand (RANKL). ${ }^{15}$ BLCs have been shown to be in close contact with osteoclasts and may also modulate bone remodeling. ${ }^{19}$ These cells have been shown to digest the protrusive nonmineralized collagen fibers mediated by matrix metalloproteinases (MMPs) and clean the bone surface in order to facilitate osteoclast attachment to their surface and subsequent resorption process. Furthermore, the activation of BLCs after osteocyte apoptosis leads to the formation of the so-called bone remodeling compartment ${ }^{17}$ where osteoclasts resorb bone without damaging the surrounding environment. Later, the osteoprogenitor cells colonize these remaining surfaces left by osteoclastic cells.

After the modulation of bone resorption, BLCs play another important role in the early stages of bone formation by entering the resorption lacunae to remove collagen fibers and debris left by osteoclasts (Figure 2B). Subsequentially to this cleaning function, BLCs secrete a layer of fibrillar collagen allowing osteoblasts to attach and deposit new osteoid. ${ }^{19}$

\section{3 Loading and bone resorption}

Osteocytes and BLCs are part of a functional syncytium which regulates communication through gap junctions during their mechanoreceptive function. ${ }^{6}$ Based on finite element analysis/models, it has previously been shown that slight loading increases bone formation and inhibits resorption. $^{20,21}$ During this function, BLCs are remodeling activators ${ }^{22}$ and promote bone resorption unless an inhibitory signal from osteocytes is present. ${ }^{23}$ Bone formation by osteoblasts is downregulated by this inhibitory signal, proportional to the mechanical loading sensed by osteocytes. ${ }^{23,24}$ Thus, an increase in bone remodeling may be observed when the strength of the inhibitory signal is low, triggered by a small generation signal or transmission failure. Bone disuse state without mechanical loading is an example of low strain-generated signal and the consequence is the activation of BLCs and bone loss. Transmission failure can be observed in cyclic loading, microdamage (microcracks) or difuse bone damage. ${ }^{23}$ Presence of microcracks or difuse damage may impair the intracellular and/or extracellular flow of signals between osteocytes and BLCs and also may increase the presence of cytokines or $\mathrm{Ca}^{++}$ions resulting in signal reduction. ${ }^{23}$ 
Moreover, excesive loading and microdamage have been related to higher osteocyte apoptosis. ${ }^{246}$ Interestingly, computer simulations stated that the inhibitory signal from osteocytes are significantly lower when cell apoptosis is present. ${ }^{25}$ Indeed, the greatest reduction in signal is when osteocyte apoptosis occurs nearest to the bone surface. ${ }^{25}$ Bone surface is mechanically more sensitive than the inner portions of the bone ${ }^{25,26}$ and therefore apoptosis location is more relevant than the total amount of cellular programmed death. ${ }^{27}$ In addition, osteocyte apoptosis is followed by an increase release of RANKL in bone leading to osteoclastogenesis and bone resorption. ${ }^{28,29}$

Under functional loading conditions, the molecular signals from osteocytes leads to a coupling of bone formation and bone resorption, being first increased in higher levels of loading and later in lower levels of strain. ${ }^{16}$ A study utilizing a simulation model by finite elements ${ }^{21}$ has demonstrated that strain-induced signals from osteocytes guide the osteoclast resorption direction, ${ }^{6}$ meanwhile unloading leads to random resorption. ${ }^{21}$ Among other factors, this osteoclast guidance is related to the differences in canalicular flow and the levels of nitric oxide (NO) in the osteocytes. ${ }^{6,30}$

$r$

\subsection{Regulation of osteocytes}

Osteocytes maintain an important role during bone formation and resorption and are the major source of RANKL in bone, ${ }^{29}$ required for osteoclast differentiation and function. ${ }^{31}$ Osteocytes also function through Wnt signaling pathways and regulate osteoblast proliferation, differentiation and survival. ${ }^{29,32}$ Wnt has also been suggested to be involved in the induction of bone formation even in cases where fibrous encapsulation predominates. ${ }^{33}$

Some pathologies may also influence RANKL expression of osteocytes. For example, the presence of estrogens promotes osteocyte viability and reduces cortical bone resorption, but lower levels has also been shown to promote osteocyte apoptosis and raise the levels of RANKL. ${ }^{34}$ Inflammatory mediators such as interleukin -I (IL-1), IL-6 and tumor necrosis-factor (TNF) alpha also increase the levels of RANKL and induce osteocyte death. ${ }^{35}$ Finally, PTH basal levels seem to maintain bone remodeling by raising RANKL and lowering osteoprotegerin (OPG) release by osteocytes. $^{29}$ 


\subsection{Bone remodeling around dental implants}

After dental implants are anchored, a sequence of immune-inflammatory responses followed by angiogenesis and eventually osteogenesis take place to achieve osseointegration. This is influenced by the implant surface characteristics owing to the ability for protein adsorption based on implant surface topography and hydrophilicity. Accordingly, thrombin and fibrinogen adhere to the implant surface. Later, neutrophils populate the implant recipient site before the monocytes and macrophages infiltrate the area. These events fulfill a key role on the early homeostasis as they release the cytokines and growth factors that stimulate collagen matrix deposition around the titanium oxide layer leading to newly-formed woven bone (usually occurs 5 days later). In a matter of 8 to 12 weeks, lamellar bone initiates the biological stability, namely osseointegration. ${ }^{1}$

As it occurs with the natural dentition, implants are subjected to soft and hard tissue remodeling after restoration delivery. Biologic width in humans around dental implants has recently been shown to be $\sim 3.5 \mathrm{~mm} .{ }^{36}$ This physiological bone remodeling mechanism to a foreign body is led by RANKL, which promotes macrophage activation into osteoclasts. When early implant marginal bone loss exposes the implant microtexture, contamination by bacterial and its byproducts is facilitated and thus, the infiltration of large proportions of CD68- and myeloperoxidase (MPO)-positive cells are capable of breaking down the peri-implant structures. ${ }^{37}$ It has been suggested that the microgap in two-piece implants might be associated with the up regulation of the inflammatory cell infiltrate leading to crestal bone loss. ${ }^{38,39}$ The abutment connection on the endosseous portion of the implant leaves a gap in a range of 10- to 50micrometers. ${ }^{38}$ A pumping effect of the fluid contained in the implant cavities might shift inwards to the peri-implant compartment due to the cyclical loading of the implant/abutment interface $\mathrm{e}^{384}$ and facilitate the colonization of the gap by putative pathogens. These organic fluids with bacteria products and endotoxins could upregulate the expression of pro-inflammatory cytokines in the peri-implant tissues and stimulate the chemotaxis of active osteoclasts. ${ }^{38}$ Over the time, leakage associated to micromovements leads to steady inflammatory reaction, ${ }^{41}$ bone loss around the implant neck and later, in the presence of biofilm, to peri-implantitis. ${ }^{42}$ It seems that internal implant connections provide better sealing than the external ones. ${ }^{42}{ }^{43}$ Tesmer et al. reported a higher number of colonies former unit (CFU) of Aggregatibacter actinomycetemcomitans and Porphyromonas gingivalis in samples of trilobe connection vs. morse cone connection in an in vitro study. ${ }^{44}$ Moreover, conical seal systems have been related to less crestal bone loss. ${ }^{43}$ Nonetheless, it remains to be elucidated the association of the gap size or microbial leakage at the implant-abutment connection with the crestal bone loss. ${ }^{45}$ In addition, it 
remains controversial the influence of the position of the implant-abutment connection on crestal bone loss. ${ }^{45}$ Even though, a greater density of neutrophils have been reported in subcrestal interfaces vs. supracrestal location. ${ }^{38,39}$ Further improvements on the implant-abutment sealing together with encouraging to use the original components might minimize the crestal bone loss associated to microgap inflammation.

As aforementioned, peri-implant implant bone undergoes remodeling after surgery trauma and due to the biological width establishment, but also it keeps in active bone remodeling during years as stimulated by the masticatory loading after the post-implantation healing. ${ }^{46-48}$ In a short-term follow-up study in dogs, Gyoon-Kim et al. reported that newly formed bone had lower ability to resist elastic, plastic and viscous deformation but higher viscoelastic capacity to absorb deformation energy than the old resorbed bone. This fact might explain why bone is able to bear the impact of masticatory loading transmitted from the implant in absence of the periodontal ligament. ${ }^{46}$ Baldassarri et al. demonstrated that bone only reaches maturity after 5 years of loading and an increase of elastic modulus and hardness have been observed during that time in human retrieved implants. ${ }^{47}$ Interestingly, a reduction in osteocyte density in samples after long period of loading have been reported, ${ }^{48}$ and a possible explanation was the limited number of cells needed to maintain bone homeostasis after bone is matured, well aligned and biomechanically competent. ${ }^{48}$ In this sense, initial healing process takes up to the first year of loading and imply the remodeling of initial woven bone and a high number of osteocytes. The second stages comprises up to the fifth year when bone matures after another active remodeling period and also a higher presence of osteocytes. Last, the third stage seems to imply a reduction in osteocytes numbers and bone remodeling. ${ }^{48}$

\section{Excess of implant torque on bone healing}

\subsection{Bone biology under implant insertion}

Adequate implant insertion torque (IT) values $(25-45 \mathrm{Ncm})$ have been suggested to prevent micro-movement that could lead to fibrous encapsulation. On the flip side, high insertion torque has also been associated with an increase in critical pressure triggering microfractures and bone necrosis (Figure 3). It has been shown in animal models that high IT elicits a complex microdamage being a strong stimulator for initiating targeted bone remodeling. Moreover, it was evidenced that cortical bone resorption occurs on the surface of differently oriented Haversian and Volkmann canals. ${ }^{49}$ This was in agreement with a radiographic, histomorphometrical and histological investigation that clearly identified that implants with a high IT $(>50 \mathrm{Ncm})$ are 
subject to greater peri-implant bone loss in the early stages of healing compared to those more passively placed. ${ }^{50}$ Additionally, a recent multiscale analysis revealed that under drilling to achieve high IT, a double layer of dead and dying osteocytes was observed when compared to low IT. ${ }^{51}$ Moreover, it was shown that osteocyte lacunar density in human cortical bone is associated with micro-cracks accumulation and porosity increase with age. ${ }^{48} 52$ This finding highlights the importance of minimizing microfractures as a consequence of high IT to predictably preserve the peri-implant bone level. Thereby, it seems highly coherent to state that the lack of primary stability may potentially jeopardize osseointegration, high IT might not favor the preservation of the peri-implant tissue level.

Finite elements studies have shown that loading increases bone formation and inhibits the resorption and that bone disuse promote bone loss, ${ }^{20}{ }^{21}$ so a contradiction between recommending low IT levels and may be observed. However, increased IT may lead to osteocyte apoptosis and consequently may promote higher levels of RANKL and VEGF secretion to the surrounding environment to remove apoptotic cells. ${ }^{29}{ }^{53}$ Higher levels of RANKL has previously been reported 100-200 microns away from microcracks and lower levels of OPG were observed up to 200 microns away from microcracks. ${ }^{53}$ Verborgt et al. reported that viable osteocytes next to microdamaged areas promoted cell apoptosis by expressing higher levels of Bax gene and that the highest levels of the anti-apoptotic protein Bcl-2 was reached 1-2 mm away from microcracks. ${ }^{54}$ Moreover, osteoclasts not only remodel disused bone, but also damaged bone like microcracks. ${ }^{55}$ ${ }^{23}$ In this area two stimuli promote osteoclast activation. ${ }^{21}$ First of all, dying osteocytes release chemotactil signals to attract osteoclasts and raise RANKL levels. Secondly, osteocyte-dead areas do not emit the osteoclast inhibitory signals. These signals might be transmitted preferently following the direction where the bone was deposited, ${ }^{21}$ triggering greater peri-implant bone loss in the crestal area.

Alveolar bone density further influences primary stability. An early publication in the field of implantology classified the maxillary ridges in four major types. ${ }^{56}$ Accordingly, denser bone is located in the anterior mandibular region, whereas more porous trabecular bone is detected in the posterior maxillary area. Recent findings seem to point to the influence of bone atrophy on bone density. ${ }^{57}$ Cortical bone has a higher elastic modulus ${ }^{58}$ and compressive strength when compared to cancellous bone. ${ }^{59}$ Nonetheless, it is worth noting that the restrained vascularity of compact bone, implying minimal to no migration of differentiating osteogenic cells, may result in peri-implant bone loss in the event of trauma. In the same way, Kristensen et 
al. reported the three main routes of osteblast recruitment during remodeling: aproximately $20 \%$ of the osteoblastic cells come from reactivation of BLC on quiescent surfaces, $50 \%$ are canopy cells from the mesenchymal bone marrow and the last third are vascular-associated osteoprogenitors like pericytes that reach the bone remodeling area by the canopies. ${ }^{60}$ Limited blood supply and abscence of bone marrow might limit the amount of osteoblast cells in the bone remodeling area, and in some cases the area may not reach the critical osteoblastic cell density needed for bone formation to occur, ${ }^{60}$ showing an arrested reversal area where only bone resorption can take place. $^{61}$

Simons et al. studied the association of the proportion of cancellous/cortical bone on marginal bone loss. ${ }^{62}$ The authors identified that higher cancellous proportion $(>50-60 \%)$, and early bone loss was significantly minimized $(\sim 0.6-0.7 \mathrm{~mm})$ when compared to implant recipient sites $(<30 \%)$ of cancellous content $(\sim 1.5 \mathrm{~mm})$. Therefore, high IT should be omitted, in particular in the presence of a thick cortical layer. In order to avoid microfractures as a consequence of high IT, tapping should be advocated.

In summary, cortical bone presents with several disadvantages when compared to trabecular bone. The limited bone supply may impair osteoprogenitors presence and the critical osteoblastic cell density required for bone repair might not be reached. ${ }^{60}$ Secondly, the crestal bone is exposed to the highest strain levels ${ }^{63}$ and correlates with the most mechanically sensitive area in bone. ${ }^{25,26}$ This highest strain levels are located on the area of first contact when two differents materials are in contact and one is loaded. ${ }^{64}$ Moreover, osteocyte apoptosis at the surface promotes a more potent resorptive signal than found in deeper bone tissues. ${ }^{25,26}$ Thirdly, according to histological reports, the highest density of osteocyte canaliculi are observed at the bone surface perpendicular to the loading force, ${ }^{6}$ therefore a greater amount of damage in this zone might be occuring. For such reasons, implant placement protocols (including IT) are crucial parameters necessitating adequate control according to their bone characteristics.

\subsection{Implant outcomes under high and low implant torque}

While the belief behind achieving high primary stability has been the goal for many clinicians based on the belief that osseointegration would be better warrantied, current clinical research seems to indicate that high implant torque might be pernicious for the peri-implant bone level. Certainly, for immediate implant placement with/-out immediate loading, solid primary stability is necessary $(>32 \mathrm{Ncm}) .{ }^{65,66}$ Nonetheless, in delayed implant placement, understanding 
the resorption process of the bundle bone and the establishment of the bone macro-architecture and bone density might dictate the drilling sequence and IT. As such, when implant placement is applied under high IT ( $\geq 50 \mathrm{Ncm}$ ), it has been shown to be more prone to marginal bone loss and recession, notably in the presence of a thin buccal bone. ${ }^{67}$ Alike, when compared to even higher IT threshold $(>70 \mathrm{Ncm})$, it was evidenced that marginal bone loss was substantially higher. ${ }^{68}$

Strikingly, an association was found statistically correlated when including all the values (up to $176 \mathrm{Ncm}$ ). This finding further reflects the role that bone structure plays and its influence on the fate of the peri-implant bone level.

For the aforementioned reasons, novel approaches for implant placement are being investigated. One example is the use of simplified drilling methods that have not seemed to jeopardize the process of osseointegration. ${ }^{67,}{ }^{68}$ For example, wider implants installed under higher IT have shown adequate secondary stability and high bone-to-implant contact (BIC); although it was demonstrated that a certain healing delaying was found due to the necrosis of the existing bone. ${ }^{69}$ Alike, findings from another group also indicated that even submerged implants inserted at $0 \mathrm{Ncm}$ torque displayed similar outcomes compared to those inserted at $30 \mathrm{Ncm}$ or 70 $\mathrm{Ncm}$ at 4 months. $^{70}$ In partial agreement, Campos et al. found that although the BIC was not affected, adequate drilling to achieve passive implantation outperformed over-/under-drilling by means of the bone area fraction occupied..$^{71}$ Hence, clinical outcomes echo the uncertain impact high IT might have on peri-implant bone loss compared to low IT. Future research are currently investigating alternative strategies including the application of osseodensification protocols, ${ }^{72}$ lasers $^{73} 74$ or ultrasound tools ${ }^{75} 767778$ to enhance osseointegration.

\section{Trauma from occlusion}

Although peri-implantitis and overload in conjunction with the host characteristics may be the major etiological agents causing late failures, ${ }^{79}$ the influence of trauma from occlusion on peri-implant disease has not been yet elucidated. ${ }^{80}$ In a systematic review based on animal studies, Chambrone et al. reported that occlusal overload may lead to bone loss in the presence of dental plaque and to a higher bone density if plaque control is performed. ${ }^{81}$ Heitz-Mayfield et al. reported in a dog study that overload did not impact on healthy implants, with no differences in BIC. $^{82}$ It is important to highlight also the series of animal studies from Miyata et al., who reported that inadequate oral hygiene and trauma from occlusion resulted in peri-implant tissue breakdown in monkeys, ${ }^{83,84}$ even in the lack of plaque-induced inflammation. ${ }^{83}$ Along these lines, a systematic review ${ }^{85}$ reported that supra-occlusal contacts on non-inflamed peri-implant bone tissues did not cause bone catabolism, whereas supra-occlusal contacts combined with 
inflammation significantly increased the plaque-induced bone loss. Accordingly, it was concluded that the effect of implant overloading on bone/implant loss in clinically well-integrated implants is poorly reported and there is not enough evidence to support a cause-and-effect relationship. ${ }^{85}$ Moreover, a clinical and radiographic study in Macaca Fascicularis confirmed that overloading might trigger the loss of osseointegration 4.5-15.5 months after the overload was commenced in the vast majority of implants examined. Interestingly, it was further shown that, although excessive marginal bone loss was observed $(1.8 \mathrm{~mm})$, no implant was lost when plaque was disrupted but in the lack of occlusal overloading. ${ }^{86}$

In summary, cautious conclusions should be done on this topic due to a limited and riskbiased literature and also due to the fact that most of the knowledge in this field is derived from animal experimental studies.

\section{Factors affecting bone metabolism}

\subsection{Cholesterol and fatty acids}

In the last three decades, the consumption of high-fat and high-cholesterol-diets have increased ${ }^{87}$ and as a consequence, the morbidity and mortality of obesity-related diseases such as cardiovascular disease and hyper-inflamed conditions have also increased. ${ }^{88,89}$ Obesity has also been related with an enhanced hazard of periodontal disease in man. ${ }^{90,91}$

Although obesity and high levels of cholesterol production have been linked for years, the relation between obesity and serum levels is low. ${ }^{92} 9394$ Similarly, the relationship between bone and body fat is complex and not totally understood to now. ${ }^{95}$ Bone marrow fat (BMF) is the accumulation of fat cells inside the bone marrow tissue. ${ }^{96}$ An inverse correlation between bone mass and BMF has been reported. ${ }^{95-98}$ Higher adipogenesis in BM may result in lower osteoblastogenesis and these adipocytes can secrete saturated fatty acids which may impair osteoblast viability by inducing apoptosis and autophagy. ${ }^{96,97}$ Adipocytes can also release proinflammatory and osteoclastogenic cytokines (e.g., TNF $\alpha$ and IL-6), adipokines and express RANKL! ${ }^{95,96,98-100}$

In other words, fatty acids ${ }^{97}$ and high levels of cholesterol ${ }^{101}$ may disturb the bone formation/bone resorption equilibrium by down-regulating the Wnt signaling pathway. ${ }^{102}$ This is probably due to the effects of higher levels of TNF $\alpha$ and sclerostin. ${ }^{103}$ Wnt pathway balances the mesenchymal stem cells differentiation by inhibiting of adipogenesis and promoting osteoblast proliferation, maturation and differentiation. ${ }^{97}$ Animal studies have shown more bone resorption, 
less bone formation and bone mass and higher levels of bone turnover markers after richcholesterol diets. ${ }^{97} 101104105106$

In addition, obesity induces a systemic inflammation condition with high levels of circulating cytokines and increased production of monocytes, neutrophils ${ }^{107,108}$ and adipose tissue macrophages. ${ }^{109,110}$ These cytokines and the accumulation of cholesterol in macrophages can alter the ratio of M1/M2 macrophages promoting an M1 pro-inflammatory environment thereby increasing the numbers of monocytes/macrophages in circulation. ${ }^{109,111}$

The influence of obesity and increased levels of cholesterol and triglycerides have been extensively described in the medical field but the effect of hyperlipidemia on dental implant osseointegration has not yet been fully elucidated. ${ }^{112}$ Significantly more peri-implant bone loss, reduced bone formation and lower strength in the bone-implant interface has previously been reported in mice after a 12 week high-fat diet. ${ }^{112}$ On the other hand, Dündar et al. (2016) reported that there was no difference in BIC 12 weeks after implant placement between rabbits following a 3-month high-fat diet versus normal diet. ${ }^{113}$ As hyperlipidemia might impair bone quantity and density, negative effects might be speculated on implant osseointegration although no conclusive revidence to date has been found.

\subsection{Vitamin D}

Vitamin D is a fat-soluble hormone that regulates calcium phosphate homeostasis and mineral bone metabolism. ${ }^{114}$ It is transformed into the active form (1,25-dyhydroxy vitamin D3) by hydroxylation, firstly in the liver and then in the kidney. ${ }^{115}$ This vitamin can stimulate osteoblast bone matrix production, coupling bone resorption to formation and optimize bone remodeling. ${ }^{116}$ It increases calcium absorption in the intestine leading to a reduction in PTH secretion and lower systemic bone resorption ${ }^{115}, 117,118$ with a possible inhibition of osteoclastogenesis. ${ }^{119}$ 1,25-dyhydroxy vitamin D3 can stimulate bone resorption by binding to osteoblast vitamin D receptors (VDR) and by altering the balance between RANKL and OPG. ${ }^{120-}$ 123

Vitamin D is a common substance in the prevention and treatment of osteoporosis but research/investigating its effects during dental implant osseointegration remains limited. ${ }^{118}$ In animals, Kelly et al. (2009) studied the osseointegration process in rats with deficiency in Vitamin D and reported lower BIC values and mechanical bone strength after 2 weeks postimplant placement. ${ }^{124}$ Noteworthy however is that implant failure might be confounded by the rising insufficiency of vitamin D prevalence in various patient populations. ${ }^{124}$ Zhou et al. (2012) reported an improved titanium screw fixation in ovariectomized rats after 8 weeks of oral 
treatment with vitamin $\mathrm{D}$, showing a significant increment of peri-implant bone density, boneimplant contact (1.5 times higher) and peri-implant trabecular microarchitecture. ${ }^{118}$ Similar results were reported in mice with chronic kidney disease (CKD), suggesting that vitamin D treatment may be an effective approach for implant placement in patients with CKD. ${ }^{125}$ Recently, the effect of topical application of vitamin D $(10 \%)^{126}$ and melatonin $(5 \%)^{127}$ solutions on the surface of immediate implants placed in dogs was evaluated. Both topical applications improved significantly new bone formation around implants and reduced crestal bone loss at 12 weeks following surgery, ${ }^{127}$ standing out the positive correlation between vitamin D and early stages of osseointegration. Therefore, these results may suggest that vitamin $\mathrm{D}$ has a protective effect on bone healing after implant insertion. ${ }^{118}$

Schulze-Spate et al. (2016), in a randomized, double-blind, placebo-controlled clinical trial in humans, reported no differences in bone formation nor in graft resorption after maxillary sinus augmentation procedure with vitamin D and calcium supplement. ${ }^{123}$ Only a difference in the number of bone-resorbing osteoclasts was assessed, finding a higher bone remodeling activity related to higher vitamin D levels. ${ }^{123}$ A retrospective study to correlate early implant failure and low serum levels of vitamin $\mathrm{D}^{128}$ showed a higher incidence of the implant failure rate in these patients but a correlation between both factors could not be determined. Therefore, vitamin D seems to improve bone health and implant healing but further research is needed to obtain an adequate level of evidence.

\subsection{Hyperglycemia}

The number of adults with diabetes in the world increased from 108 million in 1980 to 422 million in 2014. ${ }^{129}$ Type 1 diabetes (previously known as insulin-dependent, juvenile or childhood-onset) is characterized by deficient insulin production and requires daily administration of insulin. Type 2 diabetes (formerly called non-insulin-dependent or adult-onset) results from the body's ineffective use of insulin. Type 2 diabetes comprises the majority of people with diabetes around the world and is largely the result of excess body weight and physical inactivity. It is characterized by hyperglycemia, insulin resistance and relative insulin deficiency. ${ }^{130}$

Diabetes mellitus has been related to a deficient metabolism of the skeletal tissue due to a supressed osteoblastic function and lower bone formation potential, independently of the type of bone, the location and mechanical loading. ${ }^{131}$ A higher risk of implant failures have been related to uncontrolled diabetes ${ }^{132}$ and non-diagnosed diabetes might be a possible reason of failed implants for unknown reasons. ${ }^{133}$ 
Ajami et al. reported a delayed bone formation and remodeling in hyperglycemic rats. Early bone mineralization might be affected due to a compromised intra-fibrillar collagen mineralization whereas inter-fibrillar and cement line mineralization remained normal. ${ }^{134}$ Other mechanism could be the fact that diabetes promotes a hypercogulative state and a delay in fibrin clot resolution due to an increased thrombin formation, platelet activation and fibrin resistance. ${ }^{133}$

${ }^{135}$ These facts hinder platelet cytokines and growth factor release and cause a limited pericytes and endothelial migration into the implant surface together with a reduced angiogenesis. ${ }^{136}$ Moreover, hyperglycemic conditions are related to a reduction in bone formation markers like osteocalcin and bone-specific alkaline phosphatase and also bone resorption markers like Cterminal telopeptide of collagentype I (CTX). ${ }^{137}$ Serum levels of osteoprotegerin (OPG) are increased following an episode of hyperglycemia and it also leads to a lower bone density due to the accumulation of advanced glycation end products (AGEs) that affect the organic bone matrix, reduce osteoblast proliferation and function and increase osteoclast resorption. ${ }^{137}$ 138, 139

Moraschini et al. concluded in a systematic review that the rate of implant failure is not higher for diabetic subjects than non-diabetic ones, nor between type 1 and type 2 diabetic subjects. ${ }^{140}$ However, non-diabetic patients showed a statistically significant less crestal bone loss than diabetic patients. ${ }^{140}$ Furhter studies are needed to elucidate the impact of hyperglycemia upon dental implants.

\subsection{Other factors}

Not only metabolic issues can influence bone remodeling. Some patient-specific factors like medication intake might induce changes in bone cells and bone turnover and lead to bone loss around dental implants. ${ }^{141}$ Higher bone turnover seems to expose more implant surface ${ }^{140}$ and mandible might be a particularly vulnerable location. ${ }^{141}$ Serotonin reuptake inhibitors and proton pump inhibitors have been related to an increase in bone loss and higher implant failure ${ }^{142}$. so an updated and thorough medical records are advocated to avoid complications.

Other patients might present some degree of hypersensivity to titanium particles ${ }^{143}$ or ions released from implant surface. ${ }^{141}$ The corrosion of the implant surface or the dioxide layer titanium degration can release particles that induce inflammatory reactions in the peri-implant tissues. ${ }^{144}$ Aseptic loosening is the main reason for implant hip long-term failures. ${ }^{145}$ According this model, wear particles are recognized as foreign body substances and phagocytosed by macrophages. ${ }^{144}$ Later, M1 cells release inflammatory cytokines that promote osteoclastogenesis and osteolysis of the peri-implant bone. ${ }^{144}$ 


\section{Role of macrophages in bone and peri-implant breakdown and regeneration}

Macrophages play a prominent and central role in bone homeostasis and bone/biomaterial integration around dental implants. ${ }^{146}$ Specifically in bone tissues, a special subset of macrophages, termed osteal macrophages (or OsteoMacs), have recently been hypothesized to play a pivotal role in the fate of implant osseointegration. ${ }^{146}$ The general role of OsteoMacs in bone is to act as immune surveillance cells within their microenvironment. ${ }^{147,}{ }^{148}$ Yet when a foreign body biomaterial such as a dental implant is inserted trans-mucosally into the alveolar bone, a rapid accumulation of macrophages is typically found at the implant surface. ${ }^{149}$ Chehroudi et al. clearly showed that bone formation on rough titanium dental implant surfaces was routinely preceded by macrophage accumulation (prior to bone deposition). ${ }^{149}$ Despite this prominent finding, it is interesting to note that over $90 \%$ of research to date has focused on osteoblast and fibroblast behavior to material surfaces with only a small percentage $(10 \%)$ dedicated to immune cell interactions including monocytes, macrophages, osteoclasts, leukocytes and multinucleated giant cells (MNGCs). ${ }^{150}$ This major discrepancy is difficult to understand given the fact that macrophages and immune cells in general dictate how biomaterials will eventually be integrated into host tissues.

Studies from basic research have been pivotal to better understand the role of macrophages in bone biology. A series of key studies on OsteoMacs has shown that their removal during bone development is consistently found associated with a reduction in bone modeling, bone remodeling and bone repair. ${ }^{151-154}$ Furthermore, in primary osteoblast cultures (containing macrophages), the simple removal of macrophages from these in vitro systems leads to a 23 -fold decrease in the mineralization potential of bone-cells. ${ }^{153,155}$ Therefore, while basic studies have clearly pointed to their vast and substantial role in bone biology, much less information is available concerning the response of macrophages to implanted biomaterials. It is therefore pivotal to better characterize how immune cells and macrophages behave in relation to dental implant osseointegration and maintenance.

\subsection{Macrophage polarization: M1-M2 phenotypes}

While the objective of this review is not to highlight macrophage biology, it is important to note that they are some of the most plastic cell types found in the human body. They polarize completely from the classical M1 macrophage (involved in tissue pro-inflammation) towards M2 (tissue regeneration) macrophages. They may also fuse into osteoclasts and resorb bone or fuse 
into multinucleated giant cells (MNGCs) where their role remains poorly defined. ${ }^{156,157}$ Major differences between M1 and M2 macrophages is that M1 macrophages have their arginine metabolism shifted to nitric oxide (NO) and citrulline, whereas M2 macrophages are shifted towards ornithine and polyamines. ${ }^{158} \mathrm{M} 1$-macrophages produce $\mathrm{NO}$ as a main effector molecule capable of inhibiting cell proliferation, ${ }^{159}$ while M2-macrophages generate ornithine increasing cell proliferation and repair through polyamine and collagen synthesis. ${ }^{160}$

During dental implant osseointegration, classical M1-macrophages secrete a wide array of pro-inflammatory cytokines including TNF-alpha, IL-1Beta, IL-6, Il-12, MMP2, MMP9 typically induced by IFN- $\gamma$ + LPS or TNF- $\alpha$ (in vitro). ${ }^{159,}{ }^{161}$ In contrast, M2-macrophages are produced in response to IL-4 or IL-13 and also secrete a wide variety of pro-regenerative cytokines including PDGF-BB, TGB1, VEGF, IL-4, IL-10, CCL18 (Table 1). As can be expected, their polarization around implant surfaces is highly relevant for implant integration and long-term stability. Interestingly, Spiller et al. showed that macrophages can completely polarize from M2 wound-healing macrophages towards M1 pro-inflammatory macrophages within as little as 3 days and vice versa. ${ }^{162}$ Therefore, their role, especially as it relates to peri-implant infection, is extremely vital for the long-term maintenance of dental implants.

\subsection{Impact of implant surface topography and chemistry on macrophage behavior}

As previously mentioned, one area of research that has been largely omitted is the effect of implant surface material, topography, chemistry and composition on immune cell behavior. While this topic has recently been reviewed, ${ }^{146}$ it is important to note that surface roughness in general tends to increase a pro-inflammatory response. It has been shown that roughness [e.g., sandblasted acid etched (SLA)] surfaces tends to increase M1 macrophage polarization, ${ }^{163-165}$ whereas a modification to their surface chemistry has been shown to reduce this proinflammatory response (modified-SLA surfaces). ${ }^{164,} 165$ Despite this, a great deal of information concerning the behavior of monocytes/macrophages as well as their fusion to MNGCs remains unknown. A small percentage of dental implants are lost every year for yet known reasons unassociated with peri-implant infections. ${ }^{146,166}$ This is most likely caused by immune cell biocompatibility interactions not yet fully understood and future research in this field is likely to further advance of understanding of the prominent role of immune cells during early and late stages of implant osseointegration. 


\subsection{Macrophages, Immune Cells and the Foreign Body Reaction}

It has been reported that implant osseointegration is a long-term equilibrium between host immune cells and bone biomaterials. ${ }^{167-169}$ The literature showed MNGC accumulation on implant surfaces leads to biomaterial breakdown and possible implant failure/rejection. ${ }^{167-169}$ These papers provide a platform whereby implant osseointegration and eventual peri-implant bone loss is likely a direct result of a M1/M2 shift in macrophage polarization. Interestingly, invading periodontal pathogens are known to secrete lipopolysaccharides (LPS), a known and direct molecule influencing pro-inflammatory M1-macrophage polarization. ${ }^{170}$ Hence, it is important to examine foreign body reaction, equilibrium between M1 and M2 macrophage and MNGC polarization. Furthermore, these papers stressed heavily on material rejection with MNGCs accumulation on the implant surface. While MNGCs have certainly been implicated in bone biomaterial material rejection, ${ }^{167-169}$ it is interesting to note that accumulating evidence has now shown that MNGCs (which are hypothetically derived from the fusion of macrophages) are also capable of polarizing towards M1-MNGCs and M2-MNGCs. In addition, other researchers have shown that MNGCs are capable of expression M2-macrophage markers following macrophage accumulation on their biomaterial surface. ${ }^{171}$ Specifically around bone grafting materials, MNGCs have been shown to exist in stable human bone many years following their implantation ${ }^{172-174}$ and have been associated with a rapid increase in tissue vascularization. ${ }^{175-178}$ It is evident that much further research is needed to better understand their role in bone biomaterial integration and implant osseointegration.

It is therefore a necessity to accurately characterize immune cells such as macrophages and MNGCs and their interaction with dental implants, their osseointegration and their maintenance. It is likely that both cells are prone to reversibly shifting their polarization from M1/M2 macrophage/MGNCs yet little research to date has been performed as it relates to dental implants. Furthermore, many cell types are found in small spaces within the oral cavity around dental implants including osteoblasts, osteoclasts, osteocytes, fibroblasts, endothelial cells, leukocytes etc. Since macrophages (and most likely MNGCs) express high levels of cytokines, it becomes highly relevant to determine how cell-cell communication occurs between macrophages/MNGCs and other cell types (via direct cell contact or paracrine activity) during bone remodeling of implants. This field of study has thus far been left entirely unstudied yet possesses major clinical implications. 
It is also interesting to note that more recent research from the field of cardiovascular disease has shown that the calcification of arteries is a direct result of macrophages and MNGC polarization towards M2-macrophage/M2-MNGCs in the intima layers of arterial walls where they express high levels of IFN-gamma. ${ }^{179,}{ }^{180}$ It has been shown that macrophages polarize towards M2 phenotypes and begin to form ectopic bone in areas where bone should otherwise not be formed. ${ }^{146}$ Hence, it is interesting to point out that in this scenario, immune cells (such as macrophages) are dictating new bone formation. Therefore, growing evidence from many fields has now shown that macrophages playing a vast and substantial role in bone modeling and homeostasis.

\section{Conclusions}

The present review highlights some of the recent advancements in the area of bone remodeling around dental implants in both health and disease conditions. While peri-implant bone remodeling has received much attention, it remains important to better understand how loading and implant bed preparation affects bone lining cells and osteocyte viability and signaling at early stages of healing. Furthermore, the effects of systemic levels of cholesterol, fatty acids and vitamin $\mathrm{D}$ are discussed as potential responsible factors for early implant loss and long-term implant stability. We also stress out the prominent role of immune cells (e.g., OsteoMacs and multinucleated giant cells) and their impact during dental implant osseointegration and maintenance.

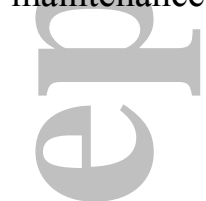

Conflict of interest: The authors do not have any financial interests, either directly or indirectly, in the products or information listed in the manuscript. This article was partially supported by the University of Michigan Periodontal Graduate Student Research Fund. 


\section{BIBLIOGRAPHY}

1. Davies JE. Understanding peri-implant endosseous healing. J Dent Educ 2003; 67: 932-949.

2. Zitzmann NU, Berglundh T, Marinello CP, Lindhe J. Experimental peri-implant mucositis in man. J Clin Periodontol 2001; 28: 517-523.

3. Sanz M, Chapple IL, Working Group 4 of the VEWoP. Clinical research on peri-

implant diseases: consensus report of Working Group 4. J Clin Periodontol 2012; 39

Suppl 12: 202-206.

4. Renvert S, Quirynen M. Risk indicators for peri-implantitis. A narrative review. Clin Oral Implants Res 2015; 26 Suppl 11: 15-44.

5. Trindade R, Albrektsson T, Tengvall P, Wennerberg A. Foreign Body Reaction

to Biomaterials: On Mechanisms for Buildup and Breakdown of Osseointegration. Clin Implant Dent Relat Res 2016; 18: 192-203.

6. Klein-Nulend J, Nijweide PJ, Burger EH. Osteocyte and bone structure. Curr Osteoporos Rep 2003; 1: 5-10.

7. Clarke B. Normal bone anatomy and physiology. Clin J Am Soc Nephrol 2008; 3 Suppl 3: S131-139.

8. Florencio-Silva R, Sasso GR, Sasso-Cerri E, Simoes MJ, Cerri PS. Biology of Bone Tissue: Structure, Function, and Factors That Influence Bone Cells. Biomed Res Int 2015; 2015: 421746.

9. Bonewald LF. The amazing osteocyte. J Bone Miner Res 2011; 26: 229-238.

10. Franz-Odendaal TA, Hall BK, Witten PE. Buried alive: how osteoblasts become osteocytes. Dev Dyn 2006; 235: 176-190.

11. Miller SC, Bowman BM, Smith JM, Jee WS. Characterization of endosteal bonelining cells from fatty marrow bone sites in adult beagles. Anat Rec 1980; 198: 163173.

12. Parfitt AM. Primary osteoporosis. Lancet 1980; 1: 773-774.

13. Miller SC, de Saint-Georges L, Bowman BM, Jee WS. Bone lining cells: structure and function. Scanning Microsc 1989; 3: 953-960; discussion 960-951.

14. Bowman BM, Miller SC. The proliferation and differentiation of the bonelining cell in estrogen-induced osteogenesis. Bone 1986; 7: 351-357.

15. Matic I, Matthews BG, Wang X, Dyment NA, Worthley DL, Rowe DW, Grcevic D, Kalajzic I. Quiescent Bone Lining Cells Are a Major Source of Osteoblasts During Adulthood. Stem Cells 2016.

16. Chow JW, Wilson AJ, Chambers TJ, Fox SW. Mechanical loading stimulates bone formation by reactivation of bone lining cells in 13-week-old rats. J Bone Miner Res 1998; 13: 1760-1767.

17. Seeman E. Bone modeling and remodeling. Crit Rev Eukaryot Gene Expr 2009; 19: 219-233.

18. Donahue HJ, McLeod KJ, Rubin CT, Andersen J, Grine EA, Hertzberg EL, Brink PR. Cell-to-cell communication in osteoblastic networks: cell line-dependent hormonal regulation of gap junction function. J Bone Miner Res 1995; 10: 881-889.

19. Everts V, Delaisse JM, Korper W, Jansen DC, Tigchelaar-Gutter W, Saftig P, Beertsen W. The bone lining cell: its role in cleaning Howship's lacunae and initiating bone formation. J Bone Miner Res 2002; 17: 77-90. 
20. Huiskes R, Ruimerman R, van Lenthe GH, Janssen JD. Effects of mechanical forces on maintenance and adaptation of form in trabecular bone. Nature 2000; 405: 704-706.

21. van Oers RF, Ruimerman R, Tanck E, Hilbers PA, Huiskes R. A unified theory for osteonal and hemi-osteonal remodeling. Bone 2008; 42: 250-259.

22. Rodan GA, Martin TJ. Role of osteoblasts in hormonal control of bone resorption--a hypothesis. Calcif Tissue Int 1981; 33: 349-351.

23. Martin RB. Toward a unifying theory of bone remodeling. Bone 2000; 26: 1-6.

24. Marotti G, Ferretti M, Muglia MA, Palumbo C, Palazzini S. A quantitative evaluation of osteoblast-osteocyte relationships on growing endosteal surface of rabbit tibiae. Bone 1992; 13: 363-368.

25. Jahani M, Genever PG, Patton RJ, Ahwal F, Fagan MJ. The effect of osteocyte apoptosis on signalling in the osteocyte and bone lining cell network: a computer simulation. J Biomech 2012; 45: 2876-2883.

26. Adachi T, Aonuma Y, Taira K, Hojo M, Kamioka H. Asymmetric intercellular communication between bone cells: propagation of the calcium signaling. Biochem Biophys Res Commun 2009; 389: 495-500.

27. Hedgecock NL, Hadi T, Chen AA, Curtiss SB, Martin RB, Hazelwood SJ. Quantitative regional associations between remodeling, modeling, and osteocyte apoptosis and density in rabbit tibial midshafts. Bone 2007; 40: 627-637.

28. Cardoso L, Herman BC, Verborgt O, Laudier D, Majeska RJ, Schaffler MB. Osteocyte apoptosis controls activation of intracortical resorption in response to bone fatigue. J Bone Miner Res 2009; 24: 597-605.

29. O'Brien CA, Nakashima T, Takayanagi H. Osteocyte control of osteoclastogenesis. Bone 2013; 54: 258-263.

30. MacIntyre I, Zaidi M, Alam AS, Datta HK, Moonga BS, Lidbury PS, Hecker M, Vane JR. Osteoclastic inhibition: an action of nitric oxide not mediated by cyclic GMP. Proc Natl Acad Sci U S A 1991; 88: 2936-2940.

31. Kong YY, Yoshida H, Sarosi I, Tan HL, Timms E, Capparelli C, Morony S, Oliveira-dos-Santos AJ, Van G, Itie A, Khoo W, Wakeham A, Dunstan CR, Lacey DL, Mak TW, Boyle WJ, Penninger JM. OPGL is a key regulator of osteoclastogenesis, lymphocyte development and lymph-node organogenesis. Nature 1999; 397: 315323.

32. Li X, Ominsky MS, Niu QT, Sun N, Daugherty B, D'Agostin D, Kurahara C, Gao Y, Cao J, Gong J, Asuncion F, Barrero M, Warmington K, Dwyer D, Stolina M, Morony S, Sarosi I, Kostenuik PJ, Lacey DL, Simonet WS, Ke HZ, Paszty C. Targeted deletion of the sclerostin gene in mice results in increased bone formation and bone strength. $J$ Bone Miner Res 2008; 23: 860-869.

33. Yin X, Li J, Chen T, Mouraret S, Dhamdhere G, Brunski JB, Zou S, Helms JA. Rescuing failed oral implants via Wnt activation. J Clin Periodontol 2016; 43: 180192.

34. Manolagas SC. Birth and death of bone cells: basic regulatory mechanisms and implications for the pathogenesis and treatment of osteoporosis. Endocr Rev 2000; 21: 115-137. 
35. Gravallese EM, Manning C, Tsay A, Naito A, Pan C, Amento E, Goldring SR. Synovial tissue in rheumatoid arthritis is a source of osteoclast differentiation factor. Arthritis Rheum 2000; 43: 250-258.

36. Tomasi C, Tessarolo F, Caola I, Wennstrom J, Nollo G, Berglundh T. Morphogenesis of peri-implant mucosa revisited: an experimental study in humans. Clin Oral Implants Res 2014; 25: 997-1003.

37. Carcuac O, Berglundh T. Composition of human peri-implantitis and periodontitis lesions. J Dent Res 2014; 93: 1083-1088.

38. Ujiie Y, Todescan R, Davies JE. Peri-implant crestal bone loss: a putative mechanism. Int J Dent 2012; 2012: 742439.

39. Hermann JS, Schoolfield JD, Schenk RK, Buser D, Cochran DL. Influence of the size of the microgap on crestal bone changes around titanium implants. A histometric evaluation of unloaded non-submerged implants in the canine mandible. J Periodontol 2001; 72: 1372-1383.

40. Insua A, Monje A, Chan HL, Zimmo N, Shaikh L, Wang HL. Accuracy of Schneiderian membrane thickness: a cone-beam computed tomography analysis with histological validation. Clin Oral Implants Res 2016.

41. Baixe S, Tenenbaum H, Etienne 0. [Microbial contamination of the implantabutment connections: Review of the literature]. Rev Stomatol Chir Maxillofac Chir Orale 2016; 117: 20-25.

42. Berberi A, Maroun D, Kanj W, Amine EZ, Philippe A. Micromovement Evaluation of Original and Compatible Abutments at the Implant-abutment Interface. J Contemp Dent Pract 2016; 17: 907-913.

43. Schmitt CM, Nogueira-Filho G, Tenenbaum HC, Lai JY, Brito C, Doring H, Nonhoff J. Performance of conical abutment (Morse Taper) connection implants: a systematic review. J Biomed Mater Res A 2014; 102: 552-574.

44. Tesmer M, Wallet S, Koutouzis T, Lundgren T. Bacterial colonization of the dental implant fixture-abutment interface: an in vitro study. J Periodontol 2009; 80: 1991-1997.

45. Passos SP, Gressler May L, Faria R, Ozcan M, Bottino MA. Implant-abutment gap versus microbial colonization: Clinical significance based on a literature review. J Biomed Mater Res B Appl Biomater 2013; 101: 1321-1328.

46. Kim DG, Kwon HJ, Jeong YH, Kosel E, Lee DJ, Han JS, Kim HL, Kim DJ. Mechanical properties of bone tissues surrounding dental implant systems with different treatments and healing periods. Clin Oral Investig 2016; 20: 2211-2220.

47. Baldassarri M, Bonfante E, Suzuki M, Marin C, Granato R, Tovar N, Coelho PG. Mechanical properties of human bone surrounding plateau root form implants retrieved after 0.3-24 years of function. J Biomed Mater Res B Appl Biomater 2012; 100: 2015-2021.

48. Monje A, Aranda L, Diaz KT, Alarcon MA, Bagramian RA, Wang HL, Catena A. Impact of Maintenance Therapy for the Prevention of Peri-implant Diseases: A Systematic Review and Meta-analysis. J Dent Res 2016; 95: 372-379.

49. Wang L, Ye T, Deng L, Shao J, Qi J, Zhou Q, Wei L, Qiu S. Repair of microdamage in osteonal cortical bone adjacent to bone screw. PLoS One 2014; 9: e89343. 
50. Duyck J, Corpas L, Vermeiren S, Ogawa T, Quirynen M, Vandamme K, Jacobs $\mathrm{R}$, Naert I. Histological, histomorphometrical, and radiological evaluation of an experimental implant design with a high insertion torque. Clin Oral Implants Res 2010; 21: 877-884.

51. Cha JY, Pereira MD, Smith AA, Houschyar KS, Yin X, Mouraret S, Brunski JB, Helms JA. Multiscale analyses of the bone-implant interface. J Dent Res 2015; 94: 482-490.

52. Vashishth D, Verborgt O, Divine G, Schaffler MB, Fyhrie DP. Decline in osteocyte lacunar density in human cortical bone is associated with accumulation of microcracks with age. Bone 2000; 26: 375-380.

53. Kennedy OD, Herman BC, Laudier DM, Majeska RJ, Sun HB, Schaffler MB. Activation of resorption in fatigue-loaded bone involves both apoptosis and active pro-osteoclastogenic signaling by distinct osteocyte populations. Bone 2012; 50: 1115-1122.

54. Verborgt 0, Tatton NA, Majeska RJ, Schaffler MB. Spatial distribution of Bax and Bcl-2 in osteocytes after bone fatigue: complementary roles in bone remodeling regulation? J Bone Miner Res 2002; 17: 907-914.

55. Lee TC, Staines A, Taylor D. Bone adaptation to load: microdamage as a stimulus for bone remodelling. J Anat 2002; 201: 437-446.

56. Misch CE. Bone classification, training keys to implant success. Dent Today 1989; 8: 39-44.

57. Monje A, Chan HL, Galindo-Moreno P, Elnayef B, Suarez-Lopez del Amo F, Wang F, Wang HL. Alveolar Bone Architecture: A Systematic Review and MetaAnalysis. J Periodontol 2015; 86: 1231-1248.

58. Rho JY, Tsui TY, Pharr GM. Elastic properties of human cortical and trabecular lamellar bone measured by nanoindentation. Biomaterials 1997; 18: 1325-1330.

59. Hayes, W.C., and Bouxsein, M.L. Biomechanics of cortical and trabecular bone: Implications for assessment of fracture risk. In Basic orthopaedic biomechanics. New York: Lippincott-Raven; 1997. p69-111

60. Kristensen HB, Andersen TL, Marcussen N, Rolighed L, Delaisse JM. Osteoblast recruitment routes in human cancellous bone remodeling. Am J Pathol 2014; 184: 778-789.

61. Andersen TL, Abdelgawad ME, Kristensen HB, Hauge EM, Rolighed L, Bollerslev J, Kjaersgaard-Andersen P, Delaisse JM. Understanding coupling between bone resorption and formation: are reversal cells the missing link? Am J Pathol 2013; 183: 235-246.

62. Simons WF, De Smit M, Duyck J, Coucke W, Quirynen M. The proportion of cancellous bone as predictive factor for early marginal bone loss around implants in the posterior part of the mandible. Clin Oral Implants Res 2015; 26: 1051-1059.

63. Naert I, Duyck J, Vandamme K. Occlusal overload and bone/implant loss. Clin Oral Implants Res 2012; 23 Suppl 6: 95-107.

64. Kitamura E, Stegaroiu R, Nomura S, Miyakawa O. Biomechanical aspects of marginal bone resorption around osseointegrated implants: considerations based 
on a three-dimensional finite element analysis. Clin Oral Implants Res 2004; 15: 401412.

65. Trisi P, Perfetti G, Baldoni E, Berardi D, Colagiovanni M, Scogna G. Implant micromotion is related to peak insertion torque and bone density. Clin Oral Implants Res 2009; 20: 467-471.

66. Ottoni JM, Oliveira ZF, Mansini R, Cabral AM. Correlation between placement torque and survival of single-tooth implants. Int J Oral Maxillofac Implants 2005; 20: 769-776.

67. Barone A, Alfonsi F, Derchi G, Tonelli P, Toti P, Marchionni S, Covani U. The Effect of Insertion Torque on the Clinical Outcome of Single Implants: A Randomized Clinical Trial. Clin Implant Dent Relat Res 2016; 18: 588-600.

68. Khayat PG, Arnal HM, Tourbah BI, Sennerby L. Clinical outcome of dental implants placed with high insertion torques (up to $176 \mathrm{Ncm}$ ). Clin Implant Dent Relat Res 2013; 15: 227-233.

69. Jimbo R, Janal MN, Marin C, Giro G, Tovar N, Coelho PG. The effect of implant diameter on osseointegration utilizing simplified drilling protocols. Clin Oral Implants Res 2014; 25: 1295-1300.

70. Rea M, Lang NP, Ricci S, Mintrone F, Gonzalez Gonzalez G, Botticelli D. Healing of implants installed in over- or under-prepared sites--an experimental study in dogs. Clin Oral Implants Res 2015; 26: 442-446.

71. Campos FE, Jimbo R, Bonfante EA, Barbosa DZ, Oliveira MT, Janal MN, Coelho PG. Are insertion torque and early osseointegration proportional? A histologic evaluation. Clin Oral Implants Res 2015; 26: 1256-1260.

72. Lahens B, Neiva R, Tovar N, Alifarag AM, Jimbo R, Bonfante EA, Bowers MM, Cuppini M, Freitas H, Witek L, Coelho PG. Biomechanical and histologic basis of osseodensification drilling for endosteal implant placement in low density bone. An experimental study in sheep. J Mech Behav Biomed Mater 2016; 63: 56-65.

73. Sisti KE, de Andres MC, Johnston D, Almeida-Filho E, Guastaldi AC, Oreffo RO. Skeletal stem cell and bone implant interactions are enhanced by LASER titanium modification. Biochem Biophys Res Commun 2016; 473: 719-725.

74. Trisi P, Berardini M, Colagiovanni M, Berardi D, Perfetti G. Laser-Treated Titanium Implants: An In Vivo Histomorphometric and Biomechanical Analysis. Implant Dent 2016; 25: 575-580.

75. Zhou HB, Hou YF, Chen WC, Shen JF, Wang J, Zhu ZM. [The acceleration of titanium implant osseointegration by low intensity pulsed ultrasound: an experimental study in rats]. Zhonghua Kou Qiang Yi Xue Za Zhi 2011; 46: 425-430.

76. Zhou H, Hou Y, Zhu Z, Xiao W, Xu Q, Li L, Li X, Chen W. Effects of LowIntensity Pulsed Ultrasound on Implant Osseointegration in Ovariectomized Rats. J Ultrasound Med 2016; 35: 747-754.

77. Ustun Y, Erdogan O, Kurkcu M, Akova T, Damlar I. Effects of low-intensity pulsed ultrasound on dental implant osseointegration: a preliminary report. Eur J Dent 2008; 2: 254-262.

78. Sedlaczek J, Lohmann CH, Lotz EM, Hyzy SL, Boyan BD, Schwartz Z. Effects of low-frequency ultrasound treatment of titanium surface roughness on osteoblast phenotype and maturation. Clin Oral Implants Res 2016. 
79. Esposito M, Hirsch JM, Lekholm U, Thomsen P. Biological factors contributing to failures of osseointegrated oral implants. (II). Etiopathogenesis. Eur J Oral Sci 1998; 106: 721-764.

80. Peri-implant mucositis and peri-implantitis: a current understanding of their diagnoses and clinical implications. J Periodontol 2013; 84: 436-443.

81. Chambrone L, Chambrone LA, Lima LA. Effects of occlusal overload on periimplant tissue health: a systematic review of animal-model studies. J Periodontol 2010; 81: 1367-1378.

82. Heitz-Mayfield LJ, Schmid B, Weigel C, Gerber S, Bosshardt DD, Jonsson J, Lang NP, Jonsson J. Does excessive occlusal load affect osseointegration? An experimental study in the dog. Clin Oral Implants Res 2004; 15: 259-268.

83. Miyata T, Kobayashi Y, Araki H, Ohto T, Shin K. The influence of controlled occlusal overload on peri-implant tissue. Part 3: A histologic study in monkeys. Int J Oral Maxillofac Implants 2000; 15: 425-431.

84. Miyata T, Kobayashi Y, Araki H, Ohto T, Shin K. The influence of controlled occlusal overload on peri-implant tissue. part 4: a histologic study in monkeys. Int J Oral Maxillofac Implants 2002; 17: 384-390.

85. Naert I, Duyck J, Vandamme K. Occlusal overload and bone/implant loss.

Clin. Oral Implants Res 2012; 23: 95-107

86. Isidor F. Influence of forces on peri-implant bone. Clin Oral Implants Res 2006; 17 Suppl 2: 8-18.

87. Tall AR, Yvan-Charvet L. Cholesterol, inflammation and innate immunity. Nat Rev Immunol 2015; 15: 104-116.

88. Devlin MJ, Rosen CJ. The bone-fat interface: basic and clinical implications of marrow adiposity. Lancet Diabetes Endocrinol 2015; 3: 141-147.

89. Cavagni J, de Macedo IC, Gaio EJ, Souza A, de Molon RS, Cirelli JA, Hoefel AL, Kucharski LC, Torres IL, Rosing CK. Obesity and Hyperlipidemia Modulate Alveolar Bone Loss in Wistar Rats. J Periodontol 2016; 87: e9-17.

90. Gorman A, Kaye EK, Apovian C, Fung TT, Nunn M, Garcia RI. Overweight and obesity predict time to periodontal disease progression in men. J Clin Periodontol 2012; 39: 107-114.

91. Nascimento GG, Leite FR, Do LG, Peres KG, Correa MB, Demarco FF, Peres MA. Is weight gain associated with the incidence of periodontitis? A systematic review and meta-analysis. J Clin Periodontol 2015; 42: 495-505.

92. Miettinen TA. Cholesterol production in obesity. Circulation 1971; 44: 842850.

93. Hobbs MS, Knuiman MW, Briffa T, Ngo H, Jamrozik K. Plasma cholesterol levels continue to decline despite the rising prevalence of obesity: population trends in Perth, Western Australia, 1980-1999. Eur J Cardiovasc Prev Rehabil 2008; 15: 319-324.

94. Bouillon K, Singh-Manoux A, Jokela M, Shipley MJ, Batty GD, Brunner EJ, Sabia S, Tabak AG, Akbaraly T, Ferrie JE, Kivimaki M. Decline in low-density lipoprotein cholesterol concentration: lipid-lowering drugs, diet, or physical activity? Evidence from the Whitehall II study. Heart 2011; 97: 923-930.

95. Bermeo S, Gunaratnam K, Duque G. Fat and bone interactions. Curr Osteoporos Rep 2014; 12: 235-242. 
96. Hardouin P, Pansini V, Cortet B. Bone marrow fat. Joint Bone Spine 2014; 81: 313-319.

97. During A, Penel G, Hardouin P. Understanding the local actions of lipids in bone physiology. Prog Lipid Res 2015; 59: 126-146.

98. Reid IR. Fat and bone. Arch Biochem Biophys 2010; 503: 20-27.

99. Melis D, Rossi A, Pivonello R, Del Puente A, Pivonello C, Cangemi G, Negri M, Colao A, Andria G, Parenti G. Reduced bone mineral density in glycogen storage disease type III: evidence for a possible connection between metabolic imbalance and bone homeostasis. Bone 2016; 86: 79-85.

100. Goto T, Nagai H, Egawa K, Kim YI, Kato S, Taimatsu A, Sakamoto T, Ebisu S, Hohsaka T, Miyagawa H, Murakami S, Takahashi N, Kawada T. Farnesyl pyrophosphate regulates adipocyte functions as an endogenous PPARgamma agonist. Biochem J 2011; 438: 111-119.

101. Soares EA, Nakagaki WR, Garcia JA, Camilli JA. Effect of hyperlipidemia on femoral biomechanics and morphology in low-density lipoprotein receptor gene knockout mice. J Bone Miner Metab 2012; 30: 419-425.

102. Baron R, Kneissel M. WNT signaling in bone homeostasis and disease: from human mutations to treatments. Nat Med 2013; 19: 179-192.

103. Baek K, Hwang HR, Park HJ, Kwon A, Qadir AS, Ko SH, Woo KM, Ryoo HM, Kim GS, Baek JH. TNF-alpha upregulates sclerostin expression in obese mice fed a high-fat diet. J Cell Physiol 2014; 229: 640-650.

104. Chen X, Wang C, Zhang K, Xie Y, Ji X, Huang H, Yu X. Reduced femoral bone mass in both diet-induced and genetic hyperlipidemia mice. Bone 2016; 93: 104112.

105. Majima T, Shimatsu A, Komatsu Y, Satoh N, Fukao A, Ninomiya K, Matsumura

T, Nakao K. Increased bone turnover in patients with hypercholesterolemia. Endocr J 2008; 55: 143-151.

106. Sanbe T, Tomofuji T, Ekuni D, Azuma T, Tamaki N, Yamamoto T. Oral administration of vitamin $\mathrm{C}$ prevents alveolar bone resorption induced by high dietary cholesterol in rats. J Periodontol 2007; 78: 2165-2170.

107. Swirski FK, Nahrendorf M. Leukocyte behavior in atherosclerosis, myocardial infarction, and heart failure. Science 2013; 339: 161-166.

108. Yvan-Charvet L, Pagler T, Gautier EL, Avagyan S, Siry RL, Han S, Welch CL, Wang N, Randolph GJ, Snoeck HW, Tall AR. ATP-binding cassette transporters and HDL suppress hematopoietic stem cell proliferation. Science 2010; 328: 1689-1693.

109. Wei H, Tarling EJ, McMillen TS, Tang C, LeBoeuf RC. ABCG1 regulates mouse adipose tissue macrophage cholesterol levels and ratio of M1 to M2 cells in obesity and caloric restriction. J Lipid Res 2015; 56: 2337-2347.

110. Hill AA, Reid Bolus W, Hasty AH. A decade of progress in adipose tissue macrophage biology. Immunol Rev 2014; 262: 134-152.

111. Fadini GP, Simoni F, Cappellari R, Vitturi N, Galasso S, Vigili de Kreutzenberg $\mathrm{S}$, Previato L, Avogaro A. Pro-inflammatory monocyte-macrophage polarization imbalance in human hypercholesterolemia and atherosclerosis. Atherosclerosis 2014; 237: 805-808. 
112. Keuroghlian A, Barroso AD, Kirikian G, Bezouglaia O, Tintut Y, Tetradis S, Moy P, Pirih F, Aghaloo T. The effects of hyperlipidemia on implant osseointegration in the mouse femur. J Oral Implantol 2015; 41: e7-e11.

113. Dundar S, Yaman F, Ozupek MF, Saybak A, Gul M, Asutay F, Kirtay M, Ozercan IH. The effects of high-fat diet on implant osseointegration: an experimental study. $J$ Korean Assoc Oral Maxillofac Surg 2016; 42: 187-192.

114. Halfon M, Phan O, Teta D. Vitamin D: a review on its effects on muscle strength, the risk of fall, and frailty. Biomed Res Int 2015; 2015: 953241.

115. Holick MF. Vitamin D deficiency. N Engl J Med 2007; 357: 266-281.

116. Kogawa M, Findlay DM, Anderson PH, Ormsby R, Vincent C, Morris HA, Atkins GJ. Osteoclastic metabolism of 25(OH)-vitamin D3: a potential mechanism for optimization of bone resorption. Endocrinology 2010; 151: 4613-4625.

117. Choukroun J, Khoury G, Khoury F, Russe P, Testori T, Komiyama Y, Sammartino G, Palacci P, Tunali M, Choukroun E. Two neglected biologic risk factors in bone grafting and implantology: high low-density lipoprotein cholesterol and low serum vitamin D. J Oral Implantol 2014; 40: 110-114.

118. Zhou C, Li Y, Wang X, Shui X, Hu J. 1,25Dihydroxy vitamin D(3) improves titanium implant osseointegration in osteoporotic rats. Oral Surg Oral Med Oral Pathol Oral Radiol 2012; 114: S174-178.

119. Sakai S, Takaishi H, Matsuzaki K, Kaneko H, Furukawa M, Miyauchi Y, Shiraishi A, Saito K, Tanaka A, Taniguchi T, Suda T, Miyamoto T, Toyama Y. 1-Alpha, 25-dihydroxy vitamin D3 inhibits osteoclastogenesis through IFN-beta-dependent NFATc1 suppression.J Bone Miner Metab 2009; 27: 643-652.

120. Leizaola-Cardesa IO, Aguilar-Salvatierra A, Gonzalez-Jaranay M, Moreu G, Sala-Romero MJ, Gomez-Moreno G. Bisphosphonates, vitamin D, parathyroid hormone, and osteonecrosis of the jaw. Could there be a missing link? Med Oral Patol Oral Cir Bucal 2016; 21: e236-240.

121. Lieben L, Masuyama R, Torrekens S, Van Looveren R, Schrooten J, Baatsen P, Lafage-Proust MH, Dresselaers T, Feng JQ, Bonewald LF, Meyer MB, Pike JW, Bouillon R, Carmeliet G. Normocalcemia is maintained in mice under conditions of calcium malabsorption by vitamin D-induced inhibition of bone mineralization. $J$ Clin Invest 2012; 122: 1803-1815.

122. Horwood NJ, Elliott J, Martin TJ, Gillespie MT. Osteotropic agents regulate the expression of osteoclast differentiation factor and osteoprotegerin in osteoblastic stromal cells. Endocrinology 1998; 139: 4743-4746.

123. Schulze-Spate U, Dietrich T, Wu C, Wang K, Hasturk H, Dibart S. Systemic vitamin $\mathrm{D}$ supplementation and local bone formation after maxillary sinus augmentation - a randomized, double-blind, placebo-controlled clinical investigation. Clin Oral Implants Res 2016; 27: 701-706.

124. Kelly J, Lin A, Wang CJ, Park S, Nishimura I. Vitamin D and bone physiology: demonstration of vitamin D deficiency in an implant osseointegration rat model. $J$ Prosthodont 2009; 18: 473-478.

125. Liu W, Zhang S, Zhao D, Zou H, Sun N, Liang X, Dard M, Lanske B, Yuan Q. Vitamin D supplementation enhances the fixation of titanium implants in chronic kidney disease mice. PLoS One 2014; 9: e95689. 
126. Salomo-Coll O, Mate-Sanchez de Val JE, Ramirez-Fernandez MP, HernandezAlfaro F, Gargallo-Albiol J, Calvo-Guirado JL. Topical applications of vitamin D on implant surface for bone-to-implant contact enhance: a pilot study in dogs part II. Clin Oral Implants Res 2016; 27: 896-903.

127. Salomo-Coll 0, de Mate-Sanchez JE, Ramirez-Fernandez MP, HernandezAlfaro F, Gargallo-Albiol J, Calvo-Guirado JL. Osseoinductive elements around immediate implants for better osteointegration: a pilot study in foxhound dogs. Clin Oral Implants Res 2016.

128. Mangano F, Mortellaro C, Mangano N, Mangano C. Is Low Serum Vitamin D Associated with Early Dental Implant Failure? A Retrospective Evaluation on 1625 Implants Placed in 822 Patients. Mediators of Inflammation 2016; 2016: 7.

129. Collaboration NCDRF. Worldwide trends in diabetes since 1980: a pooled analysis of 751 population-based studies with 4.4 million participants. Lancet 2016; 387: 1513-1530.

130. Alberti KG, Zimmet PZ. Definition, diagnosis and classification of diabetes mellitus and its complications. Part 1: diagnosis and classification of diabetes mellitus provisional report of a WHO consultation. Diabet Med 1998; 15: 539-553.

131. Retzepi M, Donos N. The effect of diabetes mellitus on osseous healing. Clin Oral Implants Res 2010; 21: 673-681.

132. Marchand F, Raskin A, Dionnes-Hornes A, Barry T, Dubois N, Valero R, Vialettes B. Dental implants and diabetes: conditions for success. Diabetes Metab 2012; 38: 14-19.

133. Ajami E, Mahno E, Mendes VC, Bell S, Moineddin R, Davies JE. Bone healing and the effect of implant surface topography on osteoconduction in hyperglycemia. Acta Biomater 2014; 10: 394-405.

134. Ajami E, Bell S, Liddell RS, Davies JE. Early bone anchorage to micro- and nano-topographically complex implant surfaces in hyperglycemia. Acta Biomater 2016; 39: 169-179.

135. Carr ME. Diabetes mellitus: a hypercoagulable state. J Diabetes Complications 2001; 15: 44-54.

136. Oprea WE, Karp JM, Hosseini MM, Davies JE. Effect of platelet releasate on bone cell migration and recruitment in vitro. J Craniofac Surg 2003; 14: 292-300.

137. King S, Klineberg I, Levinger I, Brennan-Speranza TC. The effect of hyperglycaemia on osseointegration: a review of animal models of diabetes mellitus and titanium implant placement. Arch Osteoporos 2016; 11: 29.

138. Vashishth D. The role of the collagen matrix in skeletal fragility. Curr Osteoporos Rep 2007; 5: 62-66.

139. Miyata T, Notoya K, Yoshida K, Horie K, Maeda K, Kurokawa K, Taketomi S. Advanced glycation end products enhance osteoclast-induced bone resorption in cultured mouse unfractionated bone cells and in rats implanted subcutaneously with devitalized bone particles. J Am Soc Nephrol 1997; 8: 260-270.

140. Moraschini V, Barboza ES, Peixoto GA. The impact of diabetes on dental implant failure: a systematic review and meta-analysis. Int J Oral Maxillofac Surg 2016; 45: 1237-1245. 
141. Bosshardt DD, Chappuis V, Buser D. Osseointegration of titanium, titanium alloy and zirconia dental implants: current knowledge and open questions. Periodontol 2000 2017; 73: 22-40.

142. Wu X, Al-Abedalla K, Rastikerdar E, Abi Nader S, Daniel NG, Nicolau B, Tamimi F. Selective serotonin reuptake inhibitors and the risk of osseointegrated implant failure: a cohort study. J Dent Res 2014; 93: 1054-1061.

143. Sicilia A, Cuesta S, Coma G, Arregui I, Guisasola C, Ruiz E, Maestro A. Titanium allergy in dental implant patients: a clinical study on 1500 consecutive patients. Clin Oral Implants Res 2008; 19: 823-835.

144. Pajarinen J, Kouri VP, Jamsen E, Li TF, Mandelin J, Konttinen YT. The response of macrophages to titanium particles is determined by macrophage polarization. Acta Biomater 2013; 9: 9229-9240.

145. Sundfeldt M, Carlsson LV, Johansson CB, Thomsen P, Gretzer C. Aseptic loosening, not only a question of wear: a review of different theories. Acta Orthop 2006; 77: 177-197.

146. Miron RJ, Bosshardt DD. OsteoMacs: Key players around bone biomaterials. Biomaterials 2016; 82: 1-19.

147. Heinemann DE, Lohmann C, Siggelkow H, Alves F, Engel I, Koster G. Human osteoblast-like cells phagocytose metal particles and express the macrophage marker CD68 in vitro. J Bone Joint Surg Br 2000; 82: 283-289.

148. Ruiz C, Perez E, Vallecillo-Capilla M, Reyes-Botella C. Phagocytosis and allogeneic $\mathrm{T}$ cell stimulation by cultured human osteoblast-like cells. Cell Physiol Biochem 2003; 13: 309-314.

149. Chehroudi B, Ghrebi S, Murakami H, Waterfield JD, Owen G, Brunette DM. Bone formation on rough, but not polished, subcutaneously implanted Ti surfaces is preceded by macrophage accumulation. J Biomed Mater Res A 2010; 93: 724-737.

150. Thalji G, Cooper LF. Molecular assessment of osseointegration in vitro: a review of current literature. Int J Oral Maxillofac Implants 2014; 29: e171-199.

151. Davison NL, Gamblin AL, Layrolle P, Yuan H, de Bruijn JD, Barrere-de Groot F. Liposomal clodronate inhibition of osteoclastogenesis and osteoinduction by submicrostructured beta-tricalcium phosphate. Biomaterials 2014; 35: 5088-5097.

152. Hume DA, Loutit JF, Gordon S. The mononuclear phagocyte system of the mouse defined by immunohistochemical localization of antigen F4/80: macrophages of bone and associated connective tissue. J Cell Sci 1984; 66: 189-194. 153. Chang MK, Raggatt LJ, Alexander KA, Kuliwaba JS, Fazzalari NL, Schroder K, Maylin ER, Ripoll VM, Hume DA, Pettit AR. Osteal tissue macrophages are intercalated throughout human and mouse bone lining tissues and regulate osteoblast function in vitro and in vivo. J Immunol 2008; 181: 1232-1244.

154. Favus MJ. Primer on the Metabolic Bone Disease and Disorders of Mineral Metabolism. Revue francaise d endocrinologie clinique nutrition et metabolisme 1996; 37: 553-554.

155. Pettit AR, Chang MK, Hume DA, Raggatt LJ. Osteal macrophages: a new twist on coupling during bone dynamics. Bone 2008; 43: 976-982.

156. Mosser DM, Edwards JP. Exploring the full spectrum of macrophage activation. Nat Rev Immunol 2008; 8: 958-969. 
157. Martinez FO, Gordon S. The M1 and M2 paradigm of macrophage activation: time for reassessment. F1000Prime Rep 2014; 6: 13.

158. Mills CD, Kincaid K, Alt JM, Heilman MJ, Hill AM. M-1/M-2 macrophages and the Th1/Th2 paradigm. J Immunol 2000; 164: 6166-6173.

159. MacMicking J, Xie QW, Nathan C. Nitric oxide and macrophage function. Annu Rev Immunol 1997; 15: 323-350.

160. Pesce JT, Ramalingam TR, Mentink-Kane MM, Wilson MS, El Kasmi KC, Smith AM, Thompson RW, Cheever AW, Murray PJ, Wynn TA. Arginase-1-expressing macrophages suppress Th2 cytokine-driven inflammation and fibrosis. PLoS Pathog 2009; 5: e1000371.

161. Novak ML, Koh TJ. Macrophage phenotypes during tissue repair. J Leukoc Biol 2013; 93: 875-881.

162. Spiller KL, Nassiri S, Witherel CE, Anfang RR, Ng J, Nakazawa KR, Yu T, Vunjak-Novakovic G. Sequential delivery of immunomodulatory cytokines to facilitate the M1-to-M2 transition of macrophages and enhance vascularization of bone scaffolds. Biomaterials 2015; 37: 194-207.

163. Tan KS, Qian L, Rosado R, Flood PM, Cooper LF. The role of titanium surface topography on J774A.1 macrophage inflammatory cytokines and nitric oxide production. Biomaterials 2006; 27: 5170-5177.

164. Hamlet S, Alfarsi M, George R, Ivanovski S. The effect of hydrophilic titanium surface modification on macrophage inflammatory cytokine gene expression. Clin Oral Implants Res 2012; 23: 584-590.

165. Alfarsi MA, Hamlet SM, Ivanovski S. Titanium surface hydrophilicity modulates the human macrophage inflammatory cytokine response. J Biomed Mater Res A 2014; 102: 60-67.

166. Kronström M, Svensson B, Erickson E, Houston L, Braham P, Persson GR. Humoral immunity host factors in subjects with failing or successful titanium dental implants. Journal of clinical periodontology 2000; 27: 875-882.

167. Albrektsson T, Dahlin C, Jemt T, Sennerby L, Turri A, Wennerberg A. Is marginal bone loss around oral implants the result of a provoked foreign body reaction? Clin Implant Dent Relat Res 2014; 16: 155-165.

168. Trindade R, Albrektsson T, Tengvall P, Wennerberg A. Foreign Body Reaction to Biomaterials: On Mechanisms for Buildup and Breakdown of Osseointegration. Clin Implant Dent Relat Res 2014.

169. Trindade R, Albrektsson T, Wennerberg A. Current concepts for the biological basis of dental implants: foreign body equilibrium and osseointegration dynamics. Oral Maxillofac Surg Clin North Am 2015; 27: 175-183.

170. Martinez FO, Sica A, Mantovani A, Locati M. Macrophage activation and polarization. Frontiers in bioscience: a journal and virtual library 2007; 13: 453-461.

171. Vasconcelos DP, Costa M, Amaral IF, Barbosa MA, Aguas AP, Barbosa JN. Modulation of the inflammatory response to chitosan through M2 macrophage polarization using pro-resolution mediators. Biomaterials 2015; 37: 116-123.

172. Jensen SS, Gruber R, Buser D, Bosshardt DD. Osteoclast-like cells on deproteinized bovine bone mineral and biphasic calcium phosphate: light and transmission electron microscopical observations. Clin Oral Implants Res 2015; 26: 859-864. 
173. Ghanaati S, Barbeck M, Lorenz J, Stuebinger S, Seitz O, Landes C, Kovacs AF, Kirkpatrick CJ, Sader RA. Synthetic bone substitute material comparable with xenogeneic material for bone tissue regeneration in oral cancer patients: First and preliminary histological, histomorphometrical and clinical results. Ann Maxillofac Surg 2013; 3: 126-138.

174. Lorenz J, Kubesch A, Korzinskas T, Barbeck M, Landes C, Sader RA, Kirkpatrick CJ, Ghanaati S. TRAP-Positive Multinucleated Giant Cells Are Foreign Body Giant Cells Rather Than Osteoclasts: Results From a Split-Mouth Study in Humans. J Oral Implantol 2015; 41: e257-266.

175. Luo X, Barbieri D, Davison N, Yan Y, de Bruijn JD, Yuan H. Zinc in calcium phosphate mediates bone induction: in vitro and in vivo model. Acta Biomater 2014; 10: $477-485$.

176. Bouvet-Gerbettaz S, Boukhechba F, Balaguer T, Schmid-Antomarchi H, Michiels JF, Scimeca JC, Rochet N. Adaptive immune response inhibits ectopic mature bone formation induced by BMSCs/BCP/plasma composite in immunecompetent mice. Tissue Eng Part A 2014; 20: 2950-2962.

177. Gamblin AL, Brennan MA, Renaud A, Yagita H, Lezot F, Heymann D, Trichet V, Layrolle P. Bone tissue formation with human mesenchymal stem cells and biphasic calcium phosphate ceramics: the local implication of osteoclasts and macrophages. Biomaterials 2014; 35: 9660-9667.

178. Ghanaati S, Unger RE, Webber MJ, Barbeck M, Orth C, Kirkpatrick JA, Booms P, Motta A, Migliaresi C, Sader RA, Kirkpatrick CJ. Scaffold vascularization in vivo driven by primary human osteoblasts in concert with host inflammatory cells. Biomaterials 2011; 32: 8150-8160.

179. Tintut Y, Patel J, Territo M, Saini T, Parhami F, Demer LL. Monocyte/macrophage regulation of vascular calcification in vitro. Circulation 2002; 105: 650-655.

180. Shioi A, Katagi M, Okuno Y, Mori K, Jono S, Koyama H, Nishizawa Y. Induction of bone-type alkaline phosphatase in human vascular smooth muscle cells: roles of tumor necrosis factor-alpha and oncostatin M derived from macrophages. Circ Res 2002; 91: 9-16. 


\section{Figures and legends.}

Table 1. Cytokines released by M1 and M2 macrophages.

Figure 1. Histological section of maxillary sinus lateral wall with cortical bone surface covered by bone lining cells (Immunofluorescence for Tubulin and DAPI, 20x).

Figure 2. Bone remodeling diagram. A; Cells involved in the process (modified from Weilbaecher, K. N., Guise, T. A., \& McCauley, L. K. (2011). Cancer to bone: a fatal attraction. Nature Reviews Cancer, 11(6), 411-425. B; Bone remodeling after excessive implant torque. 1) Excesive torque promotes bone damage including the osteocyte network. 2) Osteoblasts and osteoclasts are recruited from the blood, the marrow or from BLCs to populate the bone remodeling compartment. 3) Osteoclasts remove the damaged bone. 4) Bone lining cells clean the debris after osteoclast resorption. 5) BLCs secrete fibrillar collagen. 6) This collagen layer allows osteoblasts to attach. 7) Osteoblasts deposit osteoid to fill the compartment. 8) Osteoblasts trapped into the osteoid become osteocytes or bone lining cells where most undergo apoptosis (modified from Seeman E. Bone modeling and remodeling. Crit Rev Eukaryot Gene Expr 2009; 19: 219-233).

Figure 3. Bone microcracks as a consequence of excesive implant torque (modified from Cha JY, Pereira MD, Smith AA, Houschyar KS, Yin X, Mouraret S, Brunski JB, Helms JA. Multiscale analyses of the bone-implant interface. J Dent Res 2015; 94: 482-490.

Upper images (A, B, C) : Schematic of the osteotomy relative to the implant's external diameter. Image A shows an oversized preparation with the presence of a gap $\left(^{*}\right)$ between the implant and bone. This gap is filled with fibrous tissue. Image B shows a osteotomy where the implant reached low torque and a smaller gap $(*)$ is observed. Image $\mathrm{C}$ shows an undersized osteotomy that induces a high torque without gap bone-implant.

Image D: Illustration of compressive strain fields around an implant placed with low torque. Only 15-20 microns of the thread engaged in bone and promoted a small region of moderate strain. Image E: Illustration of increased compresive strain fields around an implant placed under 
increased torque. The threads engaged deeply in bone and created a larger region of high strain around the threads and the implant body. Image F: Illustration of photoelastic stress around an high-torque implant.
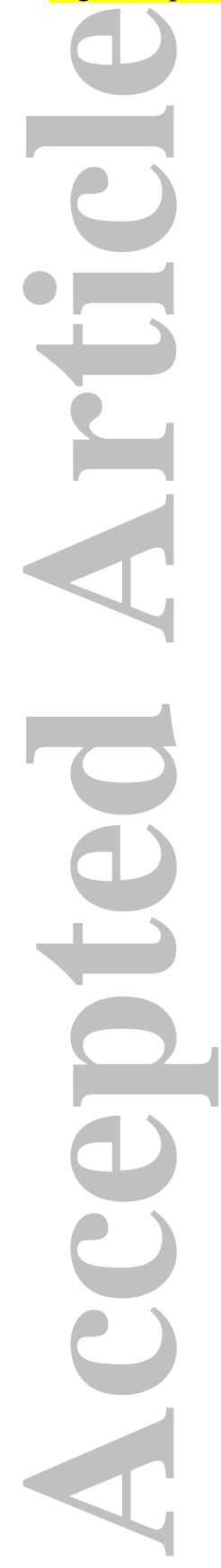

John Wiley \& Sons, Inc. 


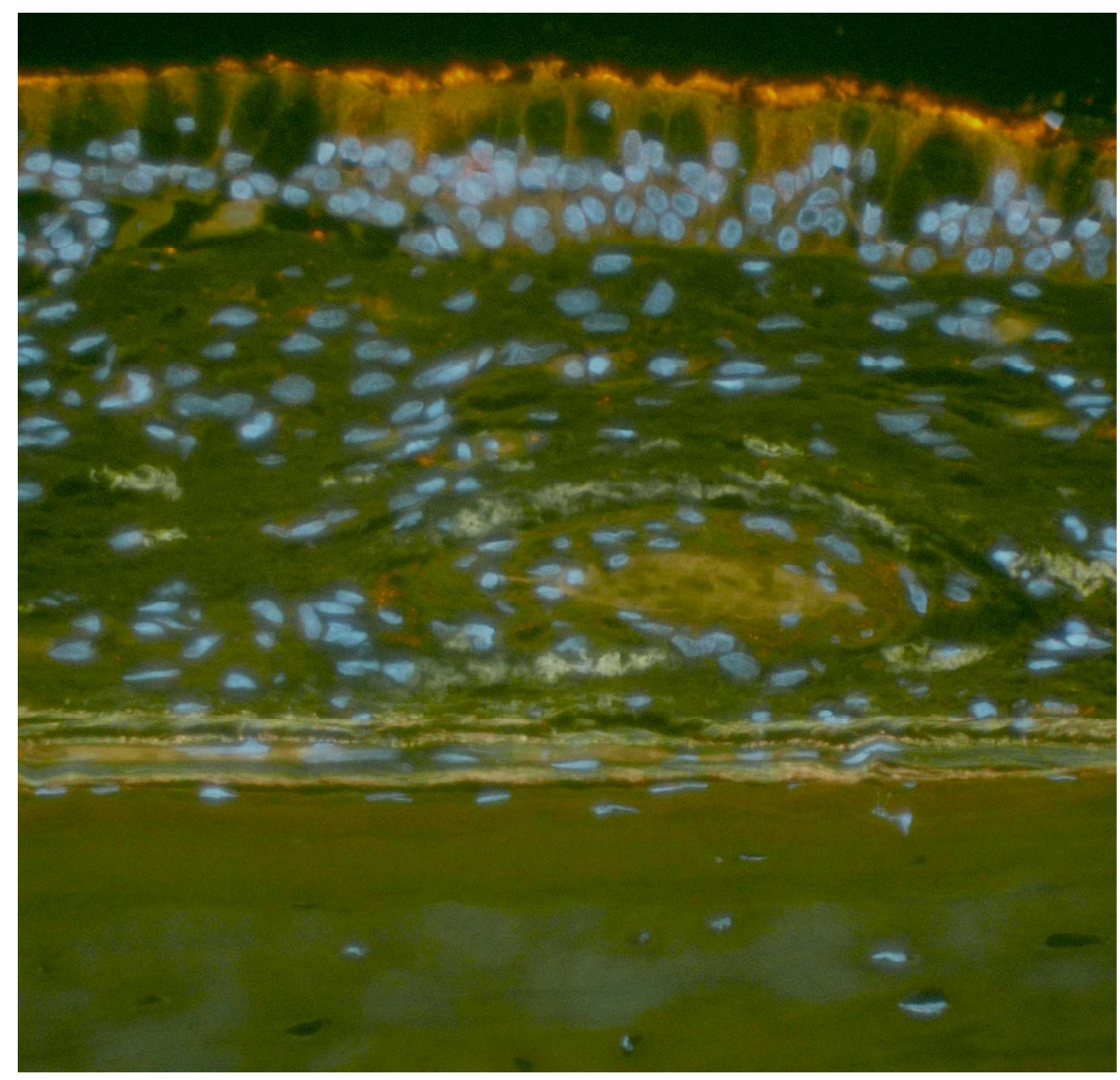

Figure 1. Histological section of maxillary sinus lateral wall with cortical bone surface covered by bone lining cells (Immunofluorescence for Tubulin and DAPI, 20x).

$$
131 \times 126 \mathrm{~mm} \text { ( } 300 \times 300 \text { DPI) }
$$

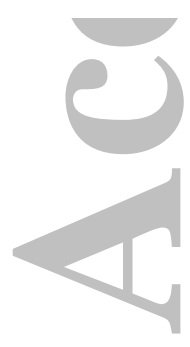

John Wiley \& Sons, Inc.

This article is protected by copyright. All rights reserved. 


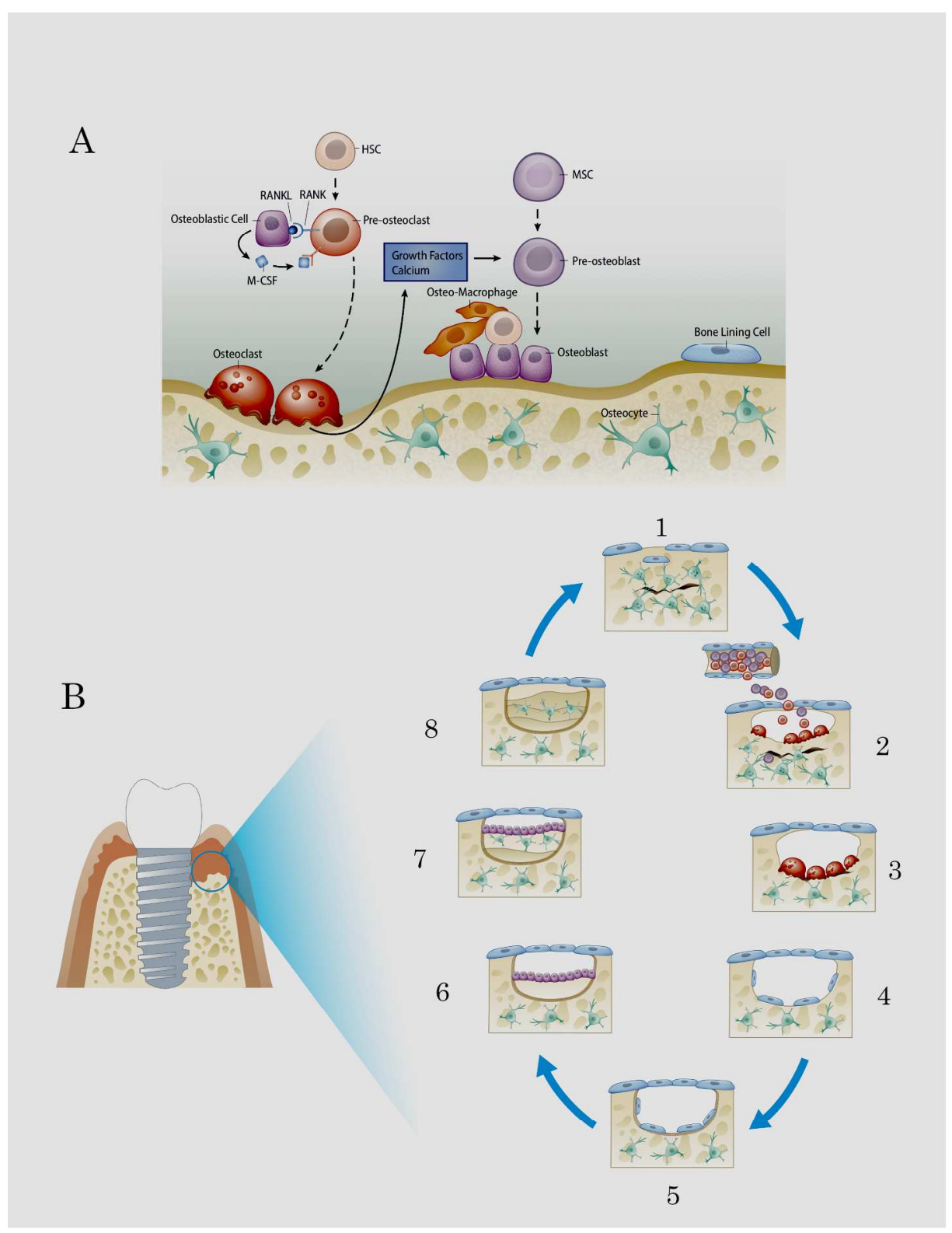

Figure 2. Bone remodeling diagram. A; Cells involved in the process (modified from Weilbaecher, K. N., Guise, T. A., \& McCauley, L. K. (2011). Cancer to bone: a fatal attraction. Nature Reviews Cancer, 11(6), 411-425. B; Bone remodeling after excessive implant torque. 1) Excesive torque promotes bone damage including the osteocyte network. 2) Osteoblasts and osteoclasts are recruited from the blood, the marrow or from BLCs to populate the bone remodeling compartment. 3) Osteoclasts remove the damaged bone. 4)

Bone lining cells clean the debris after osteoclast resorption. 5) BLCs secrete fibrillar collagen. 6) This collagen layer allows osteoblasts to attach. 7) Osteoblasts deposit osteoid to fill the compartment. 8) Osteoblasts trapped into the osteoid become osteocytes or bone lining cells where most undergo apoptosis (modified from Seeman E. Bone modeling and remodeling. Crit Rev Eukaryot Gene Expr 2009; 19: 219233).

$215 \times 279 \mathrm{~mm}(300 \times 300 \mathrm{DPI})$

John Wiley \& Sons, Inc. 

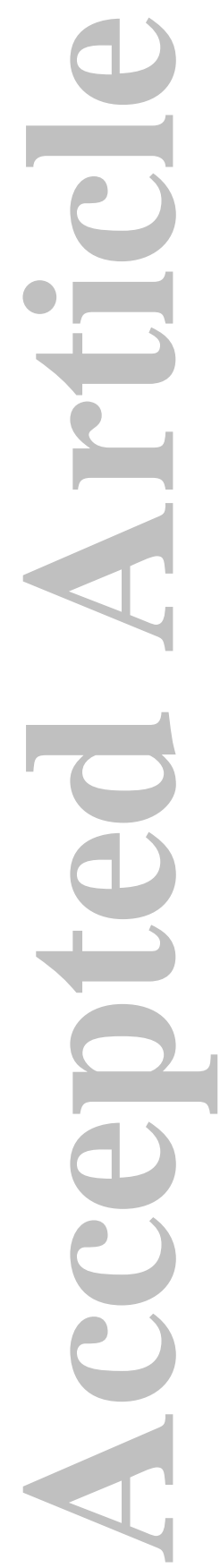

John Wiley \& Sons, Inc.

This article is protected by copyright. All rights reserved. 

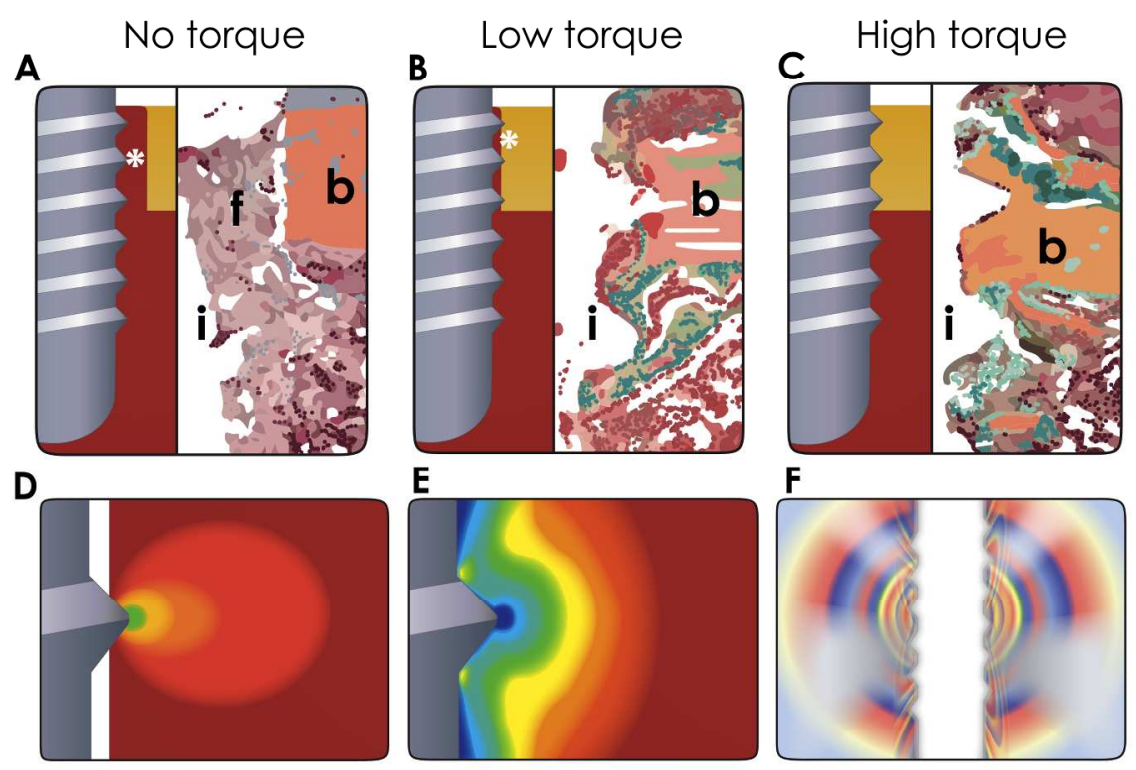

Figure 3. Bone microcracks as a consequence of excesive implant torque (modified from Cha JY, Pereira MD, Smith AA, Houschyar KS, Yin X, Mouraret S, Brunski JB, Helms JA. Multiscale analyses of the bone-implant interface. J Dent Res 2015; 94: 482-490.

Upper images (A, B, C) : Schematic of the osteotomy relative to the implant's external diameter. Image A shows an oversized preparation with the presence of a gap $\left(^{*}\right)$ between the implant and bone. This gap is filled with fibrous tissue. Image $B$ shows a osteotomy where the implant reached low torque and a smaller gap $(*)$ is observed. Image $C$ shows an undersized osteotomy that induces a high torque without gap boneimplant.

Image D: Illustration of compressive strain fields around an implant placed with low torque. Only 15-20 microns of the thread engaged in bone and promoted a small region of moderate strain. Image $\mathrm{E}$ :

Illustration of increased compresive strain fields around an implant placed under increased torque. The threads engaged deeply in bone and created a larger region of high strain around the threads and the implant body. Image F: Illustration of photoelastic stress around an high-torque implant.

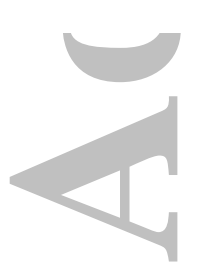

$220 \times 154 \mathrm{~mm}(300 \times 300$ DPI $)$

John Wiley \& Sons, Inc.

This article is protected by copyright. All rights reserved. 
Table 1: Markers of macrophages of M1 and M2 phenotypes, adapted from ${ }^{136}$. Those highlighted in yellow are most common markers utilized to investigate M1 and M2 macrophage polarization.

\begin{tabular}{|c|c|}
\hline M1 & M2 \\
\hline B 7 (CD80) & M130 (CD163) \\
\hline B7.2 (CD86) & CD206 (MRC1, mannose receptor) \\
\hline CCR7 (MCP-3) & FceRII (CD23) \\
\hline $\begin{array}{l}\text { CCL22 (MDC1) } \\
\text { CD64 }\end{array}$ & CD36 \\
\hline $\begin{array}{l}\text { CXCL10 (IP-10) } \\
\text { SOCS1 }\end{array}$ & IL-1 Ra \\
\hline TLR-2 & Nucleotide receptors (GPR86, GPR105, \\
\hline TLR-4 & $\mathrm{P} 2 \mathrm{Y} 8, \mathrm{P} 2 \mathrm{Y} 11, \mathrm{P} 2 \mathrm{Y} 12)$ \\
\hline FcyRIII (CD16) & C-type lectin-like receptor dectin-1 \\
\hline FcyRII (CD32) & DC-SIGN (CD209) \\
\hline LAM-1 (CD62) & DCIR (CLECSF6) \\
\hline IL-1 R1 & CLACSF13 \\
\hline IL-7R (CD127) & FIZZ1, ST2 (mouse) \\
\hline IL-2R ( $\alpha$ chain $)$ & Phagocyte receptors (SR-A, M60) \\
\hline IL-15R ( $\alpha$ chain $)$ & CXCR4, fusin (CD184) \\
\hline IL-17R (CTLA8) (CDw217) & TRAIL \\
\hline
\end{tabular}

